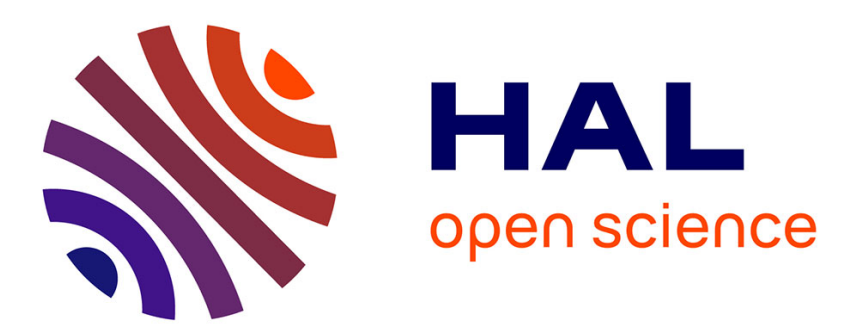

\title{
Isotope fractionation during condensation and evaporation during planet formation processes
}

\author{
Bernard Bourdon, Caroline Fitoussi
}

\section{To cite this version:}

Bernard Bourdon, Caroline Fitoussi. Isotope fractionation during condensation and evaporation during planet formation processes. ACS Earth and Space Chemistry, 2020, 4 (8), pp.1408-1423. 10.1021/acsearthspacechem.0c00139 . insu-02913146

\section{HAL Id: insu-02913146 \\ https://hal-insu.archives-ouvertes.fr/insu-02913146}

Submitted on 7 Aug 2020

HAL is a multi-disciplinary open access archive for the deposit and dissemination of scientific research documents, whether they are published or not. The documents may come from teaching and research institutions in France or abroad, or from public or private research centers.
L'archive ouverte pluridisciplinaire HAL, est destinée au dépôt et à la diffusion de documents scientifiques de niveau recherche, publiés ou non, émanant des établissements d'enseignement et de recherche français ou étrangers, des laboratoires publics ou privés. 


\title{
Isotope fractionation during condensation and
}

\section{evaporation during planet formation processes}

\author{
Bernard Bourdon* and Caroline Fitoussi
}

Laboratoire de Géologie de Lyon, ENS Lyon, CNRS, and Université Claude Bernard de Lyon, 46 Allée d'Italie, 69364 Lyon cedex 07, France

*Email : bernard.bourdon@ens-lyon.fr

KEYWORDS: Isotope, fractionation, evaporation, condensation.

ABSTRACT During the early stages of a protoplanetary disk, it is expected that the temperatures reached in the disk will lead to total or partial vaporization of dust, followed by condensation upon cooling. Similarly, chondrule forming events or giant impacts followed by magma oceans can also produce partial evaporation. Thus, moderately volatile elements can be mobilized during these thermal events, thereby leading to characteristic isotope signatures that can be used to decipher the conditions of elemental fractionation. Indeed, the magnitude of isotope fractionation of moderately volatile elements is directly modulated by the partial pressure of the element of interest. Thus, the isotope fractionation pattern for a given level of elemental depletion can be used to infer the 
pressure conditions during condensation or evaporation, thus providing strong constraints on astrophysical settings.

The observations made on moderately volatile elements or on some major elements such as $\mathrm{Mg}$, $\mathrm{Si}$, or Fe isotopes demonstrate that the isotope signature is most generally more subdued than that of vacuum evaporation producing the maximum isotope fractionation. Thus, experimental studies showing the existence of kinetic isotope fractionation associated with evaporation experiments are not sufficient to interpret cosmochemical data. In this study, we show that the evaporation or condensation coefficients may play a key role in controlling isotope fractionation. The possible role of composition and temperature on the values of evaporation/condensation coefficients are emphasized. Similarly, the role of diffusion in the gas phase leading to a back reaction of condensation during evaporation (or vice-versa) is addressed. In addition, we demonstrate that a new expression linking elemental depletion and isotope fractionation needs to be used in the case of evaporation or condensation in a closed system. Specifically, for condensation in a closed system, one needs to take into account the effect of decreasing oversaturation to model isotope fractionation. We also explored the effect of having a population of grains rather than a single grain on isotope fractionation associated with evaporation on the isotope trajectories. Last, the case of evaporation with multiple species produces a situation where the isotope fractionation pattern is modified. Overall, this study demonstrates a wealth of behaviors in isotope tracers associated with volatile loss that needs to be carefully investigated to fully exploit the information carried by them.

\section{Introduction}


Planetary bodies in the Solar System exhibit a large range in $\mathrm{K} / \mathrm{U}$ or $\mathrm{K} / \mathrm{Th}$ ratios that are systematically lower than that of the Sun's composition, indicating that these bodies are depleted in volatile elements such as $\mathrm{K}$, relative to more refractory elements such as $\mathrm{U}$ or $\mathrm{Th}^{1-4}$. This signature extends to a large range of moderately to highly volatile elements in meteorites and planets, such as Earth, Venus, Mercury and Mars. Thus, understanding the origin of volatile element depletion in planetary materials has become one of the key questions in cosmochemistry and planetary sciences. One reason for focusing on this question is perhaps that the processes leading to volatile depletion may relate to the distribution of water in the Solar System. In essence, the depletion in volatile elements reflects the complex history of planetary solids starting from initial dust to planets, where the role of thermal events must have been critical. Some of the proposed mechanisms that could explain this elemental depletion include (a) an inheritance from interstellar dust that would be volatile poor ${ }^{5,6}$; (b) early thermal processing when the protoplanetary disk was still hot ${ }^{7,8}$, (c) transient events responsible for the formation of chondrules ${ }^{9,10}$ or their precursors, although this is highly debated (e.g., ref $^{11}$ ), (d) parent-body processes such as impact events or thermal metamorphism (e.g. ref ${ }^{12}$ ) (e) outgassing during magma ocean stage ${ }^{13-16}$. A common point in all these processes is that there is a reaction between a vapor and a condensed phase (liquid or solid), and this reaction may be either kinetically driven due to strong chemical disequilibrium or it could reach equilibrium when conditions are favorable. Distinguishing between these possibilities and deciphering whether the process is kinetic or equilibrium-driven is, however, a non trivial task.

It turns out that the stable isotope signatures of volatile elements are directly affected by these processes and the corresponding isotope systems are, therefore, useful tools for deciphering the conditions leading to volatile element depletions. The most commonly used model to relate volatile 
element depletion with isotope fractionation is the Rayleigh distillation model that predicts that evaporation under kinetic conditions with low pressure leads to enrichment in heavy isotopes in the residual solid while condensation should lead to an enrichment in light isotopes in the solid. Numerous studies have indeed confirmed experimentally that evaporation under vacuum leads to large kinetic isotope fractionation for many elements ${ }^{17-23}$. However, the first sets of observations of $\mathrm{K}$ isotopes in meteorites, $\mathrm{CAI}$, chondrules and in the Moon revealed a rather different pattern with little or no fractionation with increasing $\mathrm{K}$ depletion ${ }^{24}$. More recent work has shown that, except for CAI ${ }^{25}$, the magnitude of isotope fractionations reported in planetary materials are smaller than expected for a purely kinetic Rayleigh-type loss process ( $\mathrm{Rb}, \mathrm{Zn}, \mathrm{K}, \mathrm{Mg}, \mathrm{Si}, \mathrm{Fe}, \mathrm{Cu}$ and Se) ${ }^{15,26-35}$. Thus, at all scales of planetary accretion, some processes acted to limit the large kinetic isotope fractionation expected for evaporation or condensation. The apparent discrepancy between observed isotope fractionations and elemental depletions could be resolved by the effect of the local pressure could play a role in modulating the isotope fractionations. When the local pressure becomes high enough, kinetic isotope fractionation is limited by the effect of backreaction. The situation becomes even more complex when the effect of diffusion in the condensed phase needs to be taken into account. If diffusion is sluggish, as is the case in a solid, then the relative rates of evaporation and diffusion, as expressed by the Peclet number will control whether significant isotope fractionation may arise ${ }^{36,37}$. If the evaporation rate is fast relative to the diffusion rate, then the isotope fractionation due to evaporation in the solid will be limited and the evaporating species will have more or less the composition of the bulk solid. If in reverse, diffusion rate is rapid, then kinetic fractionation will be fully expressed in the evaporating gas. Depending on the value of the Peclet number, different regimes may appear and this has been extensively studied by Ozawa et al. ${ }^{33}$ or Nagahara et al. ${ }^{38}$. Most often, for evaporation under vacuum 
conditions, the effect of equilibrium isotope fractionation during experiments can be safely neglected ${ }^{39}$. In contrast, other studies focusing on natural samples have included both the effect of kinetic and equilibrium fractionation in their formulation ${ }^{40-42}$ as the effect of pressure could not be neglected.

Despite this complexity, the study of stable isotope fractionation in planetary materials have brought a wealth of information that elemental abundances cannot provide alone. It is first useful to constrain how close is the system to saturation during evaporation or condensation (e.g. refs ${ }^{43,44}$ ). It has provided insightful views into the process of chondrule formation ${ }^{45-47}$. Notably it has become clear that volatile depletion took place under conditions rather distinct from vacuum evaporation. Similarly, volatile element isotope signatures have provided new insights into the conditions of lunar formation (e.g., ref $^{48,49}$ ) or into the volatile loss during the existence of magma oceans ${ }^{14-16}$. These studies have highlighted that the gas speciation can be inferred from the pattern of isotope fractionation and the degree of fractionation can be intrinsically linked to the rate of transport away from an evaporating surface. Our goal in this study was to build on existing work and to revisit the parameters that control the observed isotope fractionations associated with evaporation or condensation under natural conditions, rather than idealized experiments (vacuum experiments) and derive appropriate analytical expressions for predicting isotope fractionation under more realistic conditions for natural systems.

2. Isotope effects related to evaporation and condensation

The theoretical framework generally used to describe the rates of evaporation or condensation is based on the Hertz-Knudsen equation (note that this equation is not used here for describing 
shock induced vaporization). The flux of species i evaporating per unit of time per unit of surface (in $\mathrm{mol} / \mathrm{cm}^{2} / \mathrm{s}$ ) is given as

$$
\frac{d n_{i}^{s}}{d t}=\frac{\gamma_{e} P_{i, s a t}-\gamma_{c} P_{i}}{\sqrt{2 \pi m_{i} k T}}
$$

where $P_{i}$ and $P_{i, s a t}$ represent the partial pressure and the equilibrium vapor pressure of species $i$, $\mathrm{T}$ the temperature, $\mathrm{m}_{\mathrm{i}}$ the mass of species $\mathrm{i}, \mathrm{k}$ the Boltzmann constant, $\gamma_{\mathrm{e}}$ and $\gamma_{\mathrm{c}}$ are referred to as the evaporation and condensation coefficients that represent the hindrance to evaporation or condensation. In principle, if one assumes that the system can reach chemical equilibrium, then one can infer that $\gamma_{\mathrm{e}}$ and $\gamma_{\mathrm{c}}$ should be equal in equilibrium conditions because in this case $\mathrm{d} n_{i} / \mathrm{d} t$ should be equal to 0 and $\mathrm{P}_{\mathrm{i}}=\mathrm{P}_{\mathrm{i} \text {,sat. }}$. This inference is based on the principle of microscopic reversibility ${ }^{50}$, which states that, at a small scale, condensation is the reverse of evaporation at chemical equilibrium. For conditions far from equilibrium, however, this equality may not hold true because the evaporation coefficients are not constant parameters and depend, for example, on the temperature. The HK relationship can be derived by calculating the number of collisions of a vapor species to a surface, assuming a Boltzmann distribution for the mean velocity of gas species and integrating over all directions from which molecules could come from. The energetic barriers for evaporation and condensation are described by the parameters $\gamma_{\mathrm{e}}$ and $\gamma_{\mathrm{c}}$ that are dependent on the evaporating species and the composition of the condensed material that is evaporating, as well as the temperature as shown in various theoretical studies ${ }^{51-54}$. In the HK relationship, it can be seen that at constant temperature, the main parameters controlling the flux of an isotope are the partial pressure of isotope species $i$, the equilibrium vapor pressure of species, $i$ and the evaporation/condensation coefficients. Since $m_{i}$ represents the mass of the evaporating species, 
the role of speciation that will depend on the $\mathrm{P}$ and $\mathrm{T}$ conditions is also critical. It was realized at an early stage that evaporation could lead to isotope fractionation as shown in the study of Mulliken and Harkins ${ }^{55}$. If one assumes that evaporation takes place in a vacuum then, $\mathrm{P}_{\mathrm{i}}=0$ and, if one further assumes that there is negligible equilibrium isotope fractionation during evaporation, then:

$$
\frac{P_{i, s a t}}{P_{j, s a t}}=\frac{n_{i}^{s}}{n_{j}^{s}}
$$

The HK relationship written for two isotope species can be used to derive the following equation:

$$
\frac{d n_{i}^{s}}{d n_{j}^{s}}=\frac{n_{i}^{s}}{n_{j}^{s}} \frac{\gamma_{e}^{i}}{\gamma_{e}^{j}} \sqrt{\frac{m_{j}}{m_{i}}}
$$

This equation illustrates the existence of a kinetic isotope fractionation scaling as $\gamma_{e}^{i} / \gamma_{e}^{j} \sqrt{m_{j} / m_{i}}$ during evaporation. This equation can be solved and yields a classical Rayleigh equation as shown in Davis and Richter ${ }^{39}$. On the other hand, if one assumes that there is chemical equilibrium between the vapor and condensed phase, that is $\mathrm{P}_{\mathrm{i}}=\mathrm{P}_{\mathrm{i} \text {,sat }}$, then there can be an equilibrium isotope fractionation relating the isotope compositions of the vapor and of the condensed phase during evaporation:

$$
\alpha_{e q}=\frac{P_{i, s a t} / P_{j, s a t}}{n_{i}^{s} / n_{j}^{s}}
$$

This illustrates that depending on the evaporation conditions, both equilibrium isotope fractionation and kinetic isotope fractionation could play a role in controlling the observed isotope fractionation. In the next sections, we discuss the importance of the partial pressure and of the evaporation coefficients and how these parameters could affect the isotope fractionation related to evaporation.

3. Key parameters controlling isotope fractionation during condensation and evaporation 


\subsection{Evaporation and condensation coefficients}

There has been numerous attempts to describe theoretically a value for the evaporation and condensation coefficients using statistical thermodynamics, transition state theory or surface processes (e.g. refs 34-38), and these approaches have derived analytical expressions for the evaporation or condensation coefficients that are valid under specific conditions. We review briefly the ingredients that have gone into such models and their salient features. First, by definition, the evaporation coefficient represents the deviation for the rate of evaporation relative to a maximum rate given by the HK relationship. Therefore, it is commonly defined for vacuum evaporation conditions:

$$
\gamma_{e}^{i}=\frac{\varphi_{i}^{o b s}}{\varphi_{i}^{\max }}
$$

where $\varphi_{i}^{o b s}$ and $\varphi_{i}^{\max }$ represent the observed and maximum evaporative flux, respectively. The maximum evaporative flux is thus defined by the equilibrium vapor pressure of species $\mathrm{i}$. In general, crystals often show evaporation coefficient less than $1^{57}$. The theoretical derivation of Hirth and Pound ${ }^{56}$ for the evaporation coefficient of crystals predicts a minimum value of 1/3. More specifically, Hirth and Pound ${ }^{56}$ have considered that the evaporating species have different energy configurations on the surface and have shown that the main route for evaporation takes place at ledges where the surface energy is lower rather than by direct desorption from a flat surface. In this case, the rate of evaporation is also controlled by the rate of diffusion to ledges, and these authors have shown that the evaporation coefficient can be expressed as:

$$
\gamma=\frac{1}{3}+\frac{2}{3}\left(\frac{p}{p_{\text {sat }}}\right)
$$


This means that for $p=0$, the evaporation coefficient should theoretically be equal to $1 / 3$, and that under saturation conditions, the evaporation coefficient should be equal to 1 . However, this seems in disagreement with some observations indicating evaporation coefficients much lower than that threshold ${ }^{57}$.

In contrast, for liquid metals, it has been shown experimentally that $\gamma_{\mathrm{e}}$ is equal to 1 (e.g., ref $^{58}$ ). In the case of liquid oxide mixtures, it has been shown that the evaporation coefficients for pure oxides were generally less than 1 for temperatures below the melting temperature $\left(\mathrm{T}_{\mathrm{m}}\right)$, and that the evaporation coefficients converge to 1 for $\mathrm{T}=\mathrm{T}_{\mathrm{m}}{ }^{59,60}$. Shornikov ${ }^{60}$ observed that for molten pure substances such as $\mathrm{SiO}_{2}$, the evaporation coefficients are equal to 1 . In silicate melts consisting of oxide mixtures, the evaporation coefficients are however less than 1, but increase toward that 1 for increasing temperatures ${ }^{21,60-62}$. Using a model based on equilibrium vapor pressures, Alexander ${ }^{63,64}$ derived values for the evaporation coefficients of $\mathrm{MgO}, \mathrm{FeO}$ and $\mathrm{SiO}_{2}$ after having determined independently the activity of components in the silicate melts and showed their temperature dependence. In parallel, the results of Richter et al. ${ }^{21}$ have shown that the evaporation coefficients of $\mathrm{SiO}_{2}$ and $\mathrm{MgO}$ increase toward 1 with increasing temperature but this increase still happens above the melting temperature of the $\mathrm{CaO}-\mathrm{MgO}-\mathrm{Al}_{2} \mathrm{O}_{3}-\mathrm{SiO}_{2}$ mixture. Thus, the rule given by Sata and Lee ${ }^{59}$ does not seem to apply for all oxide mixtures. Molecular dynamics simulation of evaporation coefficients of binary noble gas mixtures predict that these coefficients should show rather linear trends as a function of molar fraction, indicating rather simple systematics ${ }^{65}$. However, it has not been verified that this also applies to complex silicate melts. Alexander ${ }^{64}$ has obtained variations in the values of the evaporation coefficients of $\mathrm{Na}$ and $\mathrm{K}$ for variable melt compositions, attributed to poor knowledge of their activity coefficients in the melts. In the absence of general rules for mixtures, experimental determinations have therefore been the 
main method for obtaining values of the evaporation coefficients. For example, the compilation of Fedkin et al. ${ }^{61}$ has shown that the evaporation coefficients of $\mathrm{Mg}$ and $\mathrm{SiO}$ are lower in the FeOfree system than for higher $\mathrm{FeO}$ contents at a fixed temperature. These differences could however be due to inaccuracies in activities that modify the value of equilibrium vapor pressure and hence the experimental evaporation coefficients ${ }^{64}$.

To obtain a more in-depth understanding about evaporation coefficients smaller than 1 , one can use statistical thermodynamics combined with transition state theory to derive a general expression of $\gamma_{\mathrm{e}}$ that is applicable to isotope effects. Based on transition state theory ${ }^{66-68}$, the rate of evaporation for isotope $\mathrm{i}$ from a surface is given by the following expression:

$$
j_{e}^{i}=\kappa \times n_{i, l} \frac{k T}{h} \frac{Q_{i}^{*}}{Q_{i}^{l}} e^{-\frac{\Delta E}{R T}}
$$

where $\kappa$ is a transmission coefficient taken to be equal to unity and $Q_{i}^{*}$ and $Q_{i}^{l}$ represent the partition function for the activated complex and the partition function for the liquid phase for isotope $\mathrm{i}$, respectively. $\Delta E$ is an activation energy for evaporation. It is then possible to express the partition function for the activated complex representing a species about to leave the surface as the product of the translation, rotation and vibration partition functions ${ }^{69}$ :

$$
Q_{i}^{*}=\frac{2 \pi m_{i} k T}{h^{2}} Q_{i, r}^{*} Q_{i, v}^{*}
$$

where the first term in the equation corresponds to the translational partition function confined to a surface (there are in this case two degrees of freedom for such a translation partition function), while $Q_{i, r}^{*}$ and $Q_{i, v}^{*}$ represent the rotational and vibrational partition functions, respectively. To express the chemical equilibrium between the vapor and the liquid, one can write:

$$
n_{i, g}=n_{i, l} \frac{Q_{i}^{l}}{Q_{i}^{g}} e^{-\lambda_{i} / k T}
$$


where $\lambda_{i}$ is the energy of evaporation for isotope $i$. The partition function for the vapor species is defined as:

$$
Q_{i}^{g}=\frac{\left(2 \pi m_{i} k T\right)^{3 / 2}}{h^{3}} Q_{i, r}^{g} Q_{i, v}^{g}
$$

For an atomic species, it can be written more simply:

$$
Q_{i}^{g}=\frac{\left(2 \pi m_{i} k T\right)^{3 / 2}}{h^{3}}
$$

Finally, the expression for the evaporation flux of isotope species i becomes

$$
j_{e}^{i}=\frac{k T}{h} \frac{Q_{i}^{*}}{Q_{i}^{v}} e^{-\frac{E_{i}}{k T}} e^{\frac{\lambda_{i}}{k T}}=n_{i, v} \frac{k T}{h} \frac{2 \pi m_{i} k T}{h^{2}} \frac{h^{3}}{\left(2 \pi m_{i} k T\right)^{3 / 2}} \frac{Q_{i, r}^{*} Q_{i, v}^{*}}{Q_{i, r}^{v} Q_{i, v}^{v}} e^{-\frac{E_{i}^{*}}{k T}}
$$

This expression can be rewritten as:

$$
j_{e}^{i}=n_{i, v} \frac{1}{4}\left(\frac{8 k T}{\pi m_{i}}\right)^{1 / 2} \frac{Q_{i, r}^{*} Q_{i, v}^{*}}{Q_{i, r}^{g} Q_{i, v}^{g}} e^{-\frac{E^{*}}{k T}}
$$

Thus, by identifying the value of $\gamma_{\mathrm{e}}$ with its definition in equation (5), an expression for the evaporation coefficient of isotope i becomes:

$$
\gamma_{e}^{i}=\frac{Q_{i, r}^{*} Q_{i, v}^{*}}{Q_{i, r}^{g} Q_{i, v}^{g}} e^{-\frac{E_{i}^{*}}{k T}}
$$

where $E_{i}^{*}$ represents the activation energy for condensation for isotope $\mathrm{i}$ (with $E_{i}^{*}=E_{i}-\lambda$ ). This expression is similar to the expression derived by Fujikawa et al. ${ }^{69}$ for their derivation of the condensation coefficient, except that they assumed that the vibration partition function was equal in the transition state and vapor phase. It is also similar to the derivation of Hirschwald and Stranski ${ }^{66}$ or Knacke ${ }^{68}$ for the evaporation coefficients. Knacke and Stranski ${ }^{68}$ for example neglected the 
role of activation energy and of vibrations to consider only the rotation partition function in their final expression. Thus, our expression is more general than those previously used in the literature. Note that one reason for these differences is that these authors did not investigate isotope effects related to evaporation or condensation. It is then possible to express the ratios of evaporation coefficients for isotopes $\mathrm{i}$ and $\mathrm{j}$ in the case of free evaporation with the following expression:

$$
\frac{\gamma_{e}^{i}}{\gamma_{e}^{j}}=\frac{Q_{i, r}^{*} Q_{i, v}^{*}}{Q_{i, r}^{g} Q_{i, v}^{g}} / \frac{Q_{j, r}^{*} Q_{j, v}^{*}}{Q_{j, r}^{g} Q_{j, v}^{g}} e^{-\frac{\Delta E_{i, j}^{*}}{k T}}
$$

where $\Delta E_{i_{-} j}^{*}$ represents the difference in activation energies for condensation between isotope $\mathrm{i}$ and isotope $\mathrm{j}$. Equation 15 could, in principle, be used to calculate theoretically the ratios of evaporation coefficients. The above expression shows that at high temperatures, the ratio of partition functions for isotopes $\mathrm{i}$ and $\mathrm{j}$ and the activation energy term should be equal to 1 , which means that there should no isotope fractionation induced by evaporation coefficients at high temperature. Using the derivation of Bigeleisen and Mayer $^{70}$ for temperature dependence of the ratio of vibration partition functions, the above expression should have the following temperature dependence:

$$
\frac{\gamma_{e}^{i}}{\gamma_{e}^{j}} \approx\left(1+\frac{A}{T^{2}}\right) e^{-\frac{\Delta E_{i-j}^{*}}{k T}} \approx 1-\frac{B}{T}+\frac{A}{T^{2}}
$$

Depending on the relative importance of the partition function terms and the activation energy term, the value of $\mathrm{A}$ and $\mathrm{B}$ will impose a $1 / \mathrm{T}$ or $1 / \mathrm{T}^{2}$ dependence. At high temperatures, for evaporation under vacuum conditions, the kinetic isotope fractionation factor $\alpha_{\text {kin }}$ should be simply equal to $\sqrt{m_{j} / m_{i}}$ based on equation 1 .

In general, it has been found that the kinetic isotope fractionation factors determined by experiments are not strictly equal to $\sqrt{m_{j} / m_{i}}$ which indicates that the ratio of evaporation 
coefficients is not equal to 1 at the temperatures considered, typically above $1000^{\circ} \mathrm{C}$, assuming that the evaporating species are only $\mathrm{m}_{\mathrm{i}}$ and $\mathrm{m}_{\mathrm{j}}$. If there are more species, then a more complex formalism is required (section 7) For example in the case of Mg isotopes evaporating from a CMAS melt, the value of $\alpha_{\text {kin }}$ is equal to 0.991 at $1250-1400^{\circ} \mathrm{C}$ instead of the theoretical value $0.97977=\sqrt{23.98504 / 24.98584}^{21}$. Similarly, the value of $\alpha_{\text {kin }}$ obtained by Estrade et al. ${ }^{71}$ for the evaporation of pure liquid mercury is 0.9933 instead of $0.9892=\sqrt{198 / 202}$. This is a significant offset of approximately $4.1 \%$ that can be attributed to differences in the evaporation coefficients. For silicon isotopes evaporating from a CMAS liquid, Knight et al. ${ }^{72}$ also reported kinetic isotope fractionation factor that indicates that the ratio of evaporation coefficients deviates from 1 between 2.5 and $7.9 \%$. In addition, the value of $\alpha_{\text {kin }}$ depends on the composition of the silicate melt with a smaller $\alpha_{\text {kin }}$ value observed for forsteritic melts. For silicon isotopes, the deviation from 1 for $\alpha_{\mathrm{kin}}$, which should be directly linked to the ratio of $\gamma_{e}^{i} / \gamma_{e}^{j}$, is linearly correlated with the bond length of $\mathrm{Si}-\mathrm{O}$ in the silicate melts, a parameter that should directly relate to the force constant of $\mathrm{Si}-\mathrm{O}$ in silicates (Figure 1). Interestingly, for $\mathrm{Si}$ the ratio of evaporation coefficients shows no temperature dependence, unlike what is observed for Mg isotopes. In contrast, experiments reported for $\mathrm{Ca}$ and $\mathrm{Ti}$ evaporating from molten $\mathrm{CaTiO}_{3}$ do not show any statistically significant deviation from unity for the ratio of isotope evaporation coefficients ${ }^{23}$, an observation that seems consistent with the evaporation coefficient close to 1 reported by Shornikov 60.

A temperature dependence of the kinetic isotope fractionation factor has been observed by Richter et al. ${ }^{21}$ for Mg isotopes and it can be shown based on their experimental data that the ratio of isotope fractionation factors does converge to the expected theoretical value for an infinitely large temperature (Figure 2). This would seem to confirm our theoretical expression. At lower 
temperatures, however, the ratio of evaporation coefficients is significantly different from 1 and lowers the net kinetic isotope fractionation.

Overall, these observations indicate that there can be a significant isotope fractionation effect due to evaporation coefficients that are not identical for different isotopes. Assuming that the kinetic isotope fractionation is equal to is equal to $\sqrt{m_{j} / m_{i}}$ is not a good approximation and experimental determinations should be preferred. However, the evaporation coefficients are not constant parameters and also depend on temperature and composition. Thus, before using experimental values one should check that they correspond to the expected conditions.

\subsection{Influence of local partial pressure}

The effect of local pressure is the second important parameter that has an impact on isotope fractionation during evaporation or condensation. The role of local pressure was first studied extensively in the case of water evaporation (e.g., 19, 51). More recent studies on other isotope systems explore this question from an experimental viewpoint ${ }^{73,74}$ and theoretical viewpoint $\left({ }^{20-}\right.$ 22,45. Evaporation experiments have demonstrated that in the presence of an ambient gas, the evaporation rate of solid or liquid is lower than in the vacuum ${ }^{75,76}$. Essentially, if the pressure above the evaporating surface is not equal to zero then the outward velocity of evaporating species can be reduced by collisions that will effectively reduce the transport away from the surface. In

the case of an evaporating sphere with radius $\mathrm{r}_{0}$, it has been shown by Naumann ${ }^{77}$, assuming steady-state conditions, that the net evaporative loss can be expressed as a function of the mean free path of evaporating species i by

$$
J_{i, \text { net }}=\frac{J_{i, \text { evap }}}{1+2 r_{0} / \pi \lambda}=J_{i, \text { evap }}\left(1-\frac{P_{i}}{P_{i, \text { sat }}}\right)
$$


where $\lambda$ is the mean free path for species $i$. Note that this equation is valid for free evaporation or evaporation in a viscous regime as it is based on mass conservation. The mean free path can be expressed as a function of the diffusion coefficient, which is itself a function of the ambient pressure. The mean free path can be expressed as a function of the diffusion coefficient of species $\mathrm{i}$ in the gas phase:

$$
\lambda=\frac{3 D}{\bar{v}}
$$

where $\mathrm{D}$ is the diffusion coefficient and $\bar{v}$ is the average velocity. With this expression, one can write an expression for the partial pressure of species i as a function of the diffusion coefficient for species i:

$$
P_{i}=P_{i, s a t} \frac{2 r_{0} / \pi \lambda}{\left(1+\frac{2 r_{0}}{\pi \lambda}\right)}=P_{i, s a t} \frac{2 r_{0} \bar{v} / 3 \pi D_{i}}{\left(1+\frac{2 r_{0} \bar{v}}{3 \pi D_{i}}\right)}
$$

This equation means that the value of $P_{i}$ in equation (1) is no longer an undefined parameter and that it can be calculated as a function of the mean free path and the diffusion coefficient of the gas species. For large total pressure, the mean free path $(\lambda)$ will be smaller and vice-versa. In this last equation, the diffusion coefficient $\mathrm{D}_{\mathrm{i}}$ is a direct function of the total pressure. In the case of a binary mixture, the interdiffusion coefficient can be written as ${ }^{78}$

$$
D_{i j}=\frac{3 k T}{8 P_{t o t} \sigma^{2}} \sqrt{\frac{k T}{2 \pi}\left(\frac{1}{m_{i}}+\frac{1}{m_{j}}\right)}
$$

where $\mathrm{P}_{\text {tot }}$ is the total pressure and $\sigma$ is the collisional cross section, $\mathrm{m}_{1}$ and $\mathrm{m}_{2}$ represent the masses of species 1 and 2, respectively. The expression given in equation (20) combined with the equation for the diffusion coefficient shows an explicit dependence of the ratio $\mathrm{P}_{\mathrm{i}} / \mathrm{P}_{\mathrm{i}, \text { sat }}$ on the total pressure. If a material made of a pure substance evaporates, one needs to consider the self diffusion 
coefficient of the species $i$ and in this case, the total pressure in equation (20) is equal to the partial pressure of species i and equation (20) can be rewritten as:

$$
D_{i}=\frac{3 k T}{8 P_{i} \sigma^{2}} \sqrt{\frac{k T}{\pi m_{i}}}
$$

In equation (21), $\sigma_{12}$ is a collision cross section, estimated based on the atomic radius:

$$
\sigma_{12}=\pi\left(r_{1}^{2}+r_{2}^{2}\right)
$$

It represents a probability for a molecule or an atom to encounter another. For a molecule such as $\mathrm{SnO}$ or $\mathrm{SiO}$, the molecular radius is estimated based on the sum of the atom radii and the interatomic distance $\left(\operatorname{Lilov}^{79}\right)$ :

$$
r_{S n O}=r_{S n}+r_{O}+r_{S n-O}
$$

This last equation enables a simple calculation of $\sigma_{12}$ that is not known for most species of interest. Note that the parameters $\sigma_{12}$ should be identical for isotopes $\mathrm{i}$ and $\mathrm{j}$.

An additional effect that plays a role in the case of evaporation in a vacuum is that the velocity of atoms at low pressure cannot exceed the sound speed. Thus, for a given evaporating species with a vapor pressure $\mathrm{P}_{\mathrm{i} \text {,sat, }}$, the maximum velocity will dictate a minimum effective pressure defined by a Mach number of 1 , corresponding to the velocity of gas molecules equal to the speed of sound. The corresponding pressures, as shown by Safarian and Engh ${ }^{80}$ using theoretical models of evaporation, yield values ranging between 0.19 and $0.23 \mathrm{P}_{\mathrm{i} \text {,sat. }}$

In what follows, we shall derive an expression for the isotope fractionation coefficient that includes the effect of an ambient pressure from an inert gas or from the evaporating species itself. This expression builds upon existing work, but is more general as it includes the effect of equilibrium fractionation that may become important if one is close to saturation. Similarly to 
Richter et al. ${ }^{20}$, the equation for radial transport of gas evaporating from a grain with radius $\mathrm{r}_{0}$ will be given by the following equation for radial transport:

$$
\frac{\partial C_{i}}{\partial t}=D_{i}\left(\frac{\partial^{2} C_{i}}{\partial r^{2}}+\frac{2}{r} \frac{\partial C}{\partial r}\right)
$$

In addition to this equation, a boundary condition can be written:

$$
\frac{\partial C_{i}}{\partial r}=-h\left(C_{i, s a t}-C_{i}\right)
$$

where the parameter $\mathrm{A}$ is defined as

$$
h=\frac{1}{D_{i}} \frac{\gamma_{i} R T}{\sqrt{2 \pi m_{i} R T}}
$$

The following initial condition can also be written for $\mathrm{t}=0$ :

$$
C_{i}(0, r)=C_{i, 0} \quad \text { for } r>r_{0}
$$

If the species of interest is in trace amount then the diffusion coefficient can be considered to be independent of the concentration. Under these conditions, the partial differential equation can be solved analytically to yield ${ }^{81}$ the time-dependent solution of equation (24) can be written as

$$
\begin{aligned}
\frac{C_{i}-C_{i, 0}}{C_{i, s a t}-C_{i, 0}}= & \frac{h r_{0}^{2}}{r\left(1+h r_{0}\right)}\left(\operatorname{erfc}\left(\frac{r-r_{0}}{2 \sqrt{D_{i} t}}\right)\right. \\
& \left.-e^{\left(h^{\prime}\left(r-r_{0}\right)+h^{\prime 2} D_{i} t\right)} \operatorname{erfc}\left(\frac{r-r_{0}}{2 \sqrt{D_{i} t}}+h^{\prime} \sqrt{D_{i} t}\right)\right)
\end{aligned}
$$

where $h^{\prime}$ is defined as 


$$
h^{\prime}=h+\frac{1}{r_{0}}
$$

Note that this equation differs slightly from the solution given in Richter et al. ${ }^{20}$ in its transient term. At the surface of the evaporating sphere $r=r_{0}$, this equation becomes:

$$
\frac{C_{i}-C_{i, 0}}{C_{i, s a t}-C_{i, 0}}=\frac{h r_{0}}{1+h r_{0}}\left(1-e^{h^{\prime 2} D_{i} t} \operatorname{erfc}\left(h^{\prime} \sqrt{D_{i} t}\right)\right)
$$

Using the case of $\mathrm{SiO}$ diffusion in the gas phase at $2000 \mathrm{~K}$, it can easily be shown that for a time greater than 2 s, equation (30) becomes stationary and there is a steady-state transport with a rate controlled by the diffusion coefficient. Thus, an asymptotic solution can be used instead of the time dependent solution, the steady-state solution becomes:

$$
\frac{C_{i}-C_{i, 0}}{C_{i, s a t}-C_{i, 0}}=\frac{h r_{0}}{1+h r_{0}}
$$

If one takes into account equation ( 1 , this last equation can be rewritten when $\mathrm{C}_{\mathrm{i}, 0}=0$ :

$$
C_{i}=\frac{r_{0}}{D_{i}}\left(\frac{C_{i, s a t} R T}{\sqrt{2 \pi m_{i} R T}}-\frac{C_{i} R T}{\sqrt{2 \pi m_{i} R T}}\right)=\frac{r_{0}}{D_{i}} J_{i, n e t}
$$

Using equation (1) written for two isotope species, it then is possible to calculate the net isotope fractionation factor using a derivation similar to Dauphas et al. ${ }^{42}$. We first define an effective isotope fractionation factor:

$$
\alpha_{\text {evap }}=\frac{N_{i}^{S}}{N_{j}^{S}} / \frac{J_{i}}{J_{j}}
$$

However, we did not make the following approximation as in Dauphas et al. ${ }^{42}$ : 


$$
\mathrm{J}_{i, n e t} / \mathrm{J}_{j, n e t}=\mathrm{P}_{i} / P_{j}
$$

Equation 34 assumes that the gas phase is instantaneously homogenized, which is not the case if an ambient pressure controls gas diffusion. Instead, the $P_{i} / P_{j}$ ratio was determined with the more rigorous equation 32, assuming that $\mathrm{P}_{\mathrm{i}, 0}=0$, thus, one can estimate the ratio of $\mathrm{P}_{\mathrm{i}} / \mathrm{P}_{\mathrm{j}}$ :

$$
\frac{\mathrm{P}_{i}}{P_{j}}=\frac{\mathrm{J}_{i, \text { net }} / D_{i}}{\mathrm{~J}_{j, \text { net }} / D_{j}}
$$

Using this equation, it is possible to derive a modified equation using a derivation similar to the appendix in Dauphas et al. ${ }^{42}$

$$
\alpha_{\text {evap }}=\frac{\alpha_{e q}}{\alpha_{\text {kin }}}\left[1+\frac{P_{j}}{P_{j, s a t}}\left(\alpha_{\text {kin }} \frac{D_{j}}{D_{i}}-1\right)\right]
$$

In this equation the expression $\mathrm{P}_{\mathrm{i}} / \mathrm{P}_{\mathrm{i}, \text { sat }}$ can be expressed as

$$
\frac{P_{j}}{P_{j, s a t}}=1-\frac{1}{1+\frac{\gamma_{j} r_{0}}{D_{j}} \sqrt{\frac{k T}{2 \pi m_{j}}}}
$$

Thus, the evaporation coefficient can be written in the following form that depends implicitly on the ambient pressure $\mathrm{P}_{\text {tot }}$ via equation (21):

$$
\alpha_{\text {evap }}=\frac{\alpha_{e q}}{\alpha_{\text {kin }}}\left[1+\frac{\frac{\gamma_{j} r_{0}}{D_{j}} \sqrt{\frac{k T}{2 \pi m_{j}}}}{1+\frac{\gamma_{j} r_{0}}{D_{j}} \sqrt{\frac{k T}{2 \pi m_{j}}}}\left(\alpha_{k i n} \frac{D_{j}}{D_{i}}-1\right)\right]
$$

The expression derived here for the net isotope fractionation factor during evaporation is shown to depend explicitly on the ambient pressure and fully includes the effect of diffusion in the gas phase, unlike Dauphas et al. ${ }^{42}$ and the effect of equilibrium isotope fractionation which was not the case of Davis and Richter ${ }^{39}$. The basis for understanding the role of pressure on moderating 
isotope fractionation during evaporation depends on the transport properties of atomic or molecular species in a gas. If the gas pressure is low, corresponding to a low density, the mean free path of gases is long and and a molecule can travel long distances without collisions. In this case, $P_{j} / P_{j, s a t}$ will be close to zero and $\alpha_{\text {evap }}$ should reach a value of $\alpha_{\mathrm{eq}} / \alpha_{\mathrm{kin}}$.

In contrast, for an infinitely slow diffusion in the gas phase ( $D_{\mathrm{i}} \sim 0$ in equation 37$)$, the ratio of $P_{j} / P_{j, s a t}$ can be shown to be asymptotically approaching 1 , indicating that the local partial pressure in species i should reach saturation. Similarly, a high total pressure will lead to a value of $P_{j} / P j_{\text {sat }}$ close to 1 , and if the ratio of diffusivities of isotopes can be approximated by 1 (as in ref ${ }^{20}$ ), this will overall decrease the isotope fractionation due to evaporation reaching ultimately $\alpha_{e q}$. In this case, the net isotope fractionation should be of limited amplitude at high temperature, but given the uncertainties obtained by mass spectrometry analytical methods, this may be detectable. Our formulation also shows implicitly the role of an ambient gas that will increase the value of the diffusion coefficient. If the diffusion takes place in the Solar Nebula where the dominant gas is $\mathrm{H}_{2}$, then $\alpha_{\text {evap }}$ should be equal to $\alpha_{\mathrm{eq}} \mathrm{D}_{\mathrm{j}} / \mathrm{D}_{\mathrm{i}}$. The value of the isotope fractionation coefficient will be closer to 1 and for the case of ${ }^{30} \mathrm{Si} /{ }^{28} \mathrm{Si}$ will be equal to

$$
\alpha_{\text {evap }} \approx \alpha_{e q} D_{j} / D_{i} \approx \sqrt{\frac{28(30+2)}{30(28+2)}}=0.998
$$

This was already pointed out in Richter et al. ${ }^{22}$. This value is significantly closer to 1 than the classical kinetic parameter $\sqrt{28 / 30}=0.966$. Yet it is sufficiently different from 1 that it should be taken into account.

4. Modelling isotope fractionation during condensation 
The study of condensation has been more limited than that of evaporation possibly due to the difficulty in producing condensates experimentally. Using an approach similar to that used for evaporation, Davis and Richter ${ }^{39}$ have shown that the net isotope fractionation factor for condensation as a function of the partial pressure of species i can be approximated as

$$
\alpha^{\prime}-1 \approx(\alpha-1)\left(1-\frac{P_{i, s a t}}{P_{i}}\right)
$$

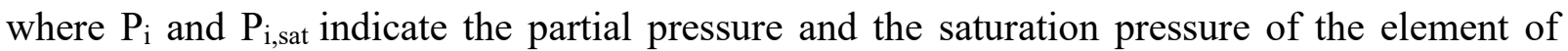
interest. If the oversaturation is relatively small, which corresponds to conditions close to equilibrium, then it is no longer valid to assume that the magnitude of the equilibrium isotope fractionation is negligible. In this case, a new set of equations has to be derived to take into account the effect of equilibrium fractionation. It should be noted that the equation of Davis and Richter ${ }^{39}$ neglected this effect. This problem has in fact been dealt with by Jouzel and Merlivat ${ }^{40}$ for the case of water isotope fractionation during the condensation of rainwater and Dauphas et al. ${ }^{42}$ in their Si isotope study. However, the equations that were used in ref ${ }^{40}$ do not correspond to the formal treatment of condensation described by the Hertz-Knudsen equations. For isotopes $\mathrm{i}$ and $\mathrm{j}$ the net condensation flux can be written:

$$
J_{n e t}^{i}=\frac{d n_{i}}{d t}=\frac{\gamma_{c}\left(P_{i}-P_{i, s a t}\right)}{\sqrt{2 \pi m_{i} k T}}
$$

where $\gamma_{c}$ is the condensation coefficient. We then make the assumption that there is equilibrium isotope fractionation at the interface between the gas and the condensate, and this equilibrium can be written: 


$$
\frac{P_{i, s a t}}{P_{j, s a t}} / \frac{d m_{i}^{\text {cond }}}{d m_{j}^{\text {cond }}}=\frac{P_{i, s a t}}{P_{j, s a t}} / \frac{J_{i, n e t}}{J_{j, n e t}}=\alpha_{e q}
$$

Similarly to the case of of evaporation, a net isotope fractionation factor for condensation can be defined as:

$$
\alpha_{\text {cond }}=\frac{\alpha_{k i n}}{1+\frac{P_{j, s a t}}{P_{j}}\left(\frac{\alpha_{k i n}}{\alpha_{e q}}-1\right)}
$$

$P_{j, s a t} / P_{j}$ is an oversaturation and should be less than 1 for net condensation to take place. In this equation, the value of $P_{j, s a t} / P_{j}$ is not specified a priori but in the case of a closed system with finite size, it can be estimated as shown below. For this reason, we have developed a model valid for a closed system where the amount of volatile species $i$ is limited. In this case, the partial pressure should decrease due to loss of the equilibrium vapor phase by condensation, until it reaches the vapor pressure. Thus, our set of equations describes isotope fractionation during condensation in a closed system under isothermal conditions, i.e., the saturation pressure is constant and the partial pressure decreases as a result of condensation. The system would be more complex if we had in addition assumed that there was cooling. In this case, there could be sustained oversaturation as the cooling would lower the value of ${ }^{\mathrm{Pi} \text {,sat }}$ (e.g., ref ${ }^{82}$ ). Similarly if the vaporization reaction involves several species with variable partial pressures, a different formalism would be required (see Section 6 for an example). Here, we assume that the fraction of condensed vapor (F) can be written as: 


$$
F=\frac{n_{i}-n_{i, s a t}}{n_{i, 0}-n_{i, s a t}}
$$

This equation shows that $F=1$ at the beginning of condensation, that $F=0$ at the end and that the number of moles in the vapor is equal to the saturation conditions for a fixed volume. If we define $\beta=n_{i, s a t} / n_{i, 0}$ then it is possible to express the ratio $P_{i, s a t} / P_{i}$ as a function of $F$ and $\beta$. We first divide the numerator and denominator by $n_{i}$

$$
F=\frac{1-\frac{P_{i, s a t}}{P_{i}}}{\frac{1}{\beta} \frac{P_{i, s a t}}{P_{i}}-\frac{P_{i, s a t}}{P_{i}}}
$$

By solving for $\mathrm{P}_{\mathrm{i}, \mathrm{sat}} / \mathrm{P}_{\mathrm{i}}$, one obtains

$$
\frac{P_{i, s a t}}{P_{i}}=\frac{\beta}{\beta+F(1-\beta)}
$$

Thus, the equation 43 can be rewritten as a function of $\mathrm{F}$ and $\beta$, with $\mathrm{F}$ being a variable parameter during condensation:

$$
\alpha_{\text {cond }}=\frac{\alpha_{\text {kin }}}{1+\frac{\beta}{F(1-\beta)+\beta}\left(\frac{\alpha_{\text {kin }}}{\alpha_{e q}}-1\right)}
$$

In this context, the isotope fractionation factor is variable during condensation because the value of $\mathrm{F}$ constantly evolves during condensation. The variation in the isotope composition of the vapor can be written as 


$$
\frac{d X_{j}}{X_{j}}=\alpha_{\text {cond }} \frac{d X_{i}}{X_{i}}
$$

Where $X_{i}$ and $X_{j}$ denotes the abundances of isotopes $\mathrm{i}$ and $\mathrm{j}$, respectively. By expressing the value of $\alpha_{\text {eff }}$ as a function of $X_{i}$ and $X_{i, 0}$, it is possible to integrate equation 48 to yield the isotope composition of the vapor defined as $X_{j} / X_{i}$

$$
\begin{gathered}
\frac{d X_{j}}{X_{j}}=\frac{\alpha_{k i n} X_{i}}{X_{1}+\beta\left(\frac{\alpha_{k i n}}{\alpha_{e q}}-1\right) X_{i, 0}} \frac{d X_{i}}{X_{i}} \\
R_{j, i}^{v}=\frac{R_{j, i}^{0}}{(F(1-\beta)+\beta)}\left(\frac{F(1-\beta)-\beta \frac{\alpha_{k i n}}{\alpha_{e q}}}{1+\beta\left(\frac{\alpha_{k i n}}{\alpha_{e q}}-1\right)}\right)^{\alpha_{k i n}}
\end{gathered}
$$

Using a simple mass balance equation, it is then possible to derive the isotope composition of the condensate

$$
R_{j, i}^{c}=\frac{R_{j, i}^{0}-F R_{j, i}^{v}}{1-F}
$$

Compared with the formulation of Davis and Richter ${ }^{39}$ that is commonly used in the literature, this new formulation shows that the isotope fractionation factor varies with the condensed fraction F. As the system nears saturation $\left(P_{i}=P_{i, s a t}\right)$, the isotope fractionation factor becomes equal to $\alpha_{\text {eq. }}$ Depending on the value of $\beta$, the effective isotope fractionation factor could actually be much smaller than the kinetic fractionation factor that is commonly used to describe condensation processes. For illustrative purpose, we have shown the shape of the condensation curve compared 
with a classical Rayleigh fractionation curve assuming purely kinetic effects in the case of $\mathrm{Zn}$ isotopes (Figure 3). The predicted magnitude of isotope fractionation is notably smaller with the new model presented here and may account for the limited isotope fractionation observed in many isotope systems $24,28,29,83$. The general shape of the fractionation curve is also modified substantially. One could note that in the case of a cooling system, the problem would be more complex with a variable value of $\mathrm{n}_{\mathrm{i}, \text { sat }}$. In such a case, one would need to specify a given cooling rate to solve the equations and they would mostly likely have to be integrated numerically.

An example where this model for condensation may apply is the $\mathrm{Zn}$ isotopes reported for carbonaceous chondrites by Luck et al. ${ }^{26}$. If one plots the $\mathrm{Zn}$ isotope data as a function of a $\mathrm{Zn}$ concentration normalized to that of CI chondrites, the observed trend shows a slightly convex shape. This data set was interpreted by Albarède ${ }^{84}$ as due to the effect of partial condensation, as the $\mathrm{Zn}$ depleted chondrites showed an enrichment in light $\mathrm{Zn}$ isotopes. However, if one assumes that this trend can be explained by partial condensation, then a model curve using the classical Rayleigh distillation model should show a concave shape as illustrated in Figure 4 using the equation (39), as given in Davis and Richter ${ }^{39}$. In contrast, using the equation derived above, the model curve gives a better fit and lends support to the validity of this model. It should be mentioned that other interpretations have been proposed to explain the $\mathrm{Zn}$ isotopes observations. For example, Pringle et al. ${ }^{28}$ have explained this trend by mixing of components with variable $\mathrm{Zn}$ isotope compositions. While such a mixing model also fits the observations, it provides no explanation for the existence of a component that is enriched in light isotopes. The idea of mixing was supported by the existence of a correlation between $\delta^{64} \mathrm{Zn}$ and $\varepsilon^{54} \mathrm{Cr}$ for carbonaceous chondrites ${ }^{28}$ and this trend could be due to mixing between components with different nucleosynthetic signatures. As the proposed interpretation for the variations in $\varepsilon^{54} \mathrm{Cr}$ is that a thermal processing in the 
protoplanetary disk has variably affected the carriers of $\mathrm{Cr}$ nucleosynthetic anomalies ${ }^{85}$, the existence of a correlation linking $\mathrm{Cr}$ and $\mathrm{Zn}$ isotopes may simply reflect the effect of differing thermal processing of nucleosynthetic carriers. Indeed, this thermal processing if it also involved partial condensation of a volatilized Zn could produce the trends shown in Figures 5 and 6 of ref 28 .

In summary, our new set of equations provides a more realistic framework for describing isotope fractionation during condensation in a closed system. As an example, the concept of a closed system may be valid for a system that is large enough, or at least where the boundary of the system may be remote enough to feel any mass loss or mass exchange. This may apply to a cooling protoplanetary disk. As more data sets become available, this framework may become useful, although experimental devices to study condensation in fully controlled experiments are still lacking.

5. Modelling isotope fractionation during isothermal evaporation in a closed-system

Most existing models for isotope fractionation during evaporation assume that the evaporated species is free to escape to space (e.g., ref ${ }^{20,63}$ ). Alternatively, there is no accumulation of the evaporation species in the space above the evaporating phase $\mathrm{e}^{25,36}$. This is done either by setting a pressure equal to zero at infinite distance ${ }^{20}$ or by assuming evaporation in vacuum. In this section, we have considered an endmember case of a closed system which has not been dealt with in previous studies. As the diffusion of volatile species is not instantaneous, it is interesting to consider the end-member case of a closed system (similar to the case presented for condensation in section 4) for the case of evaporation. In the present model, we consider that the solid (or liquid) evaporates in a closed system at constant temperature until it reaches the equilibrium vapor 
pressure. With this condition, the pressure as a function of the evaporated fraction can be estimated. Furthermore, we consider that evaporation can be influenced both by kinetic isotope fractionation and equilibrium isotope fractionation and in this case, the effective isotope fractionation factor can be expressed as (see derivation in section 3.2):

$$
\alpha_{\text {evap }}=\frac{\alpha_{e q}}{\alpha_{k i n}}\left(1+\left[\frac{P_{j}}{P_{j, s a t}}\right]\left(\frac{D_{j}}{D_{i}} \alpha_{k i n}-1\right)\right)
$$

For isotope i, one can write the following mass balance equation, assuming no volatile species in the starting gas: $\quad N_{i}^{g}+N_{i}^{s}=N_{i}^{0}$

where $N_{i}$ represents a number of moles per unit of volume. With this notation, the fraction of isotope $\mathrm{j}$ in the gas phase can be defined as

$$
f=\frac{N_{j}^{g}}{N_{j, s a t}}
$$

With this definition, $f$ ranges from 0 to 1 upon evaporation (i.e., $f=1$ when evaporation is completed). The Hertz-Knudsen equation for evaporation can then be written for isotope $\mathrm{i}$ and isotope $\mathrm{j}$ and these equations can then be used to express the variation in isotope ratio during evaporation using the effective isotope fractionation factor:

$$
\frac{d N_{i}^{s}}{d N_{j}^{s}}=\frac{1}{\alpha_{e v a p}} \frac{N_{i}^{s}}{N_{j}^{S}}
$$

This equation can be integrated if one expresses the dependence of $\alpha_{\text {eff }}$ as a function of $N_{j}^{S}$. This is done by rewriting a new explicit equation for $\mathrm{f}$ using the mass balance equation (52):

$$
f=\frac{N_{j}^{g}}{N_{j, s a t}}=\frac{N_{j}^{0}-N_{j}^{s}}{N_{j, s a t}}
$$

Or: 


$$
f=\gamma-\frac{N_{j}^{s}}{N_{j, s a t}}
$$

where $\gamma$ is defined as

$$
\gamma=\frac{N_{j}^{0}}{N_{j, s a t}}
$$

Thus, $\gamma$ represents a potential oversaturation parameter, if one assumes total evaporation of the solid in the considered volume. With this notation, equation 54 can be written directly as

$$
\frac{d N_{i}^{s}}{d N_{j}^{s}}=\frac{\alpha_{k i n} / \alpha_{e q}}{1+\left[\gamma-\frac{N_{j}^{s}}{N_{j, s a t}}\right]\left(\frac{D_{j}}{D_{i}} \alpha_{k i n}-1\right)} \frac{N_{i}^{s}}{N_{j}^{s}}
$$

This equation can then be integrated using the separation of variables and expressed as a function of $\mathrm{f}$ :

$$
\begin{aligned}
R_{i j}^{S}=R_{i j}^{0} \times(1 & -f / \gamma)^{\frac{\alpha_{k i n}}{\alpha_{e q}\left(1+\gamma\left(\alpha_{K}-1\right)\right)}-1} \\
& \times\left(\frac{1+\gamma\left(\alpha_{K}-1\right)-\left(\alpha_{K}-1\right)(\gamma-f)}{1+\gamma\left(\alpha_{K}-1\right)-\left(\alpha_{K}-1\right) \gamma}\right)^{-\frac{\alpha_{K}}{\alpha_{e q}\left(1+\gamma\left(\alpha_{K}-1\right)\right)}}
\end{aligned}
$$

Using a simple mass balance, it is then possible to derive the equation for the isotope composition of the vapor phase:

$$
R_{i j}^{g}=\frac{R_{i j}^{0}-f / \gamma R_{i j}^{S}}{1-f / \gamma}
$$

For the sake of illustration, the curves corresponding to such evaporation models are shown in Figure 5 for various values of undersaturation defined as $P_{i, 0} / P_{i, s a t}$. The closed system model shows a rather different shape compared with Rayleigh distillation curves that have a concave shape, showing a decreasing isotope fractionation as evaporated species reach saturation. As mentioned above, this model may be used to describe experiments in a closed system or serve as an end- 
member case for geophysical or astrophysical settings. For example, it could be a useful point of comparison for the evaporation of a magma ocean with a thick atmosphere limiting the escape rate of evaporating species ${ }^{15,36}$. Under these conditions, the oversaturation may be reach a state close to equilibrium that has strong similarities with the problem treated here. The advantage of our model is that it does not depend on a complex atmospheric model that may be prone to uncertainties (e.g. $\left.\operatorname{ref}^{86}\right)$.

6. Evaporation with a population of evaporating drops-transient regime-collective effect

As described above, evaporation in a closed system may act to buffer isotope fractionation compared with a pure Rayleigh evaporation. This system could also be similar to a large chondrule forming region as in Cuzzi and Alexander ${ }^{87}$ where the diffusion outside of the region may be limited. A similar situation may arise when one considers the evaporation of a population of $\mathrm{N}$ grains that will have influence on the local pressure, thereby leading to backward condensation flux and lowering the net evaporative flux. These effects have been examined in the fluid dynamics literature (e.g., ref ${ }^{88}$ ) where the presence of other drops lowers the overall rate of evaporation. However, these effects were never considered in the case of isotope fractionation. In the cosmochemical context, this situation may arise during chondrule formation where there may be a local dust to gas enrichment, as argued in Ebel and Grossman ${ }^{89}$. To consider this case, we assumed that the grains have a density $d_{N}$ representing the number of grains of radius $r$ per unit volume ( $=N / V$ where $V$ is the volume), that is large enough such that the gas loss at the boundary of the considered domain does not influence the overall budget. We make the assumption that the local field of pressures is rapidly equilibrated at a local scale because the density of grains is such that pressure gradients do not persist. In this context, the net evaporation flux can be written as 


$$
\frac{d N_{i}^{g}}{d t}=J \times N=4 \pi r^{2} N \frac{\left(P_{i, s a t}-P_{i}\right)}{\sqrt{2 \pi m_{i} R T}}
$$

Where $N$ is the number of spheres with radius $r$ and $N_{i}^{g}$ is the number of moles in the gas phase. If the pressure is low, then the ideal gas law can be used to relate the partial pressure to $\mathrm{n}_{\mathrm{i}}$, the number of moles of gas i:

$$
P_{i}=\frac{N_{i}}{V} R T
$$

Hence the above differential equation can be rewritten:

$$
\frac{d N_{i}^{g}}{d t}=4 \pi r^{2} N \frac{P_{i, s a t}}{\sqrt{2 \pi m_{i} R T}}-4 \pi r^{2} d_{N} \frac{N_{i}^{g} R T}{\sqrt{2 \pi m_{i} R T}}
$$

This equation can be solved analytically, and the solution can be expressed as a function of the partial pressure of component $\mathrm{i}$ is:

$$
P_{i}=P_{i, s a t}\left(1-e^{-4 \pi r^{2} d_{N} \sqrt{\frac{8 \pi R T}{m_{i}} t}}\right)
$$

This expression for $\mathrm{P}_{\mathrm{i}}$ can be used to determine the variation in the effective isotope fractionation in the vapor or the condensed phase. This particular equation may apply to the case of evaporation for a population of chondrules with a local pressure building up with time.

In the case of a trace element ( $\mathrm{Zn}$ will be taken as an example), the value of $\mathrm{P}_{\mathrm{i}, \mathrm{sat}}$ will not be a fixed value during the evaporation process and $P_{i, s a t}$, the equilibrium vapor pressure, can be expressed as a function of activity:

$$
a_{Z n O}=\frac{P_{Z n O, s a t}}{P_{Z n O}^{*}}
$$


where $P_{Z n O} *$ is the vapor pressure for a pure species ( $\mathrm{ZnO}$ in this case). The main vaporizing species is however $\mathrm{Zn}(\mathrm{g})$ rather than $\mathrm{ZnO}(\mathrm{g})$ and there is the following equilibrium in the gas phase:

$$
Z n(g)+O(g) \leftrightarrows Z n O(g)
$$

The reaction constant can then be written:

$$
K_{Z n O}=\frac{P_{Z n O(g)}}{P_{Z n(g)} P_{O(g)}}
$$

One first needs to calculate $\mathrm{P}_{\mathrm{Zn} \text {,sat }}$ using the equilibrium with $\mathrm{ZnO}(\mathrm{g})$ :

$$
\gamma_{Z n O} C_{Z n O}=K_{Z n O} \frac{P_{Z n, s a t} P_{O_{2}}^{1 / 2}}{P_{Z n O}^{*}}
$$

$C_{Z n O}$ is the concentration of species $\mathrm{i}$ in the solid/condensed phase phase $\left(n_{Z n O}^{S} / v\right)$ and $v$ is the volume of an individual grain assumed to be invariant during evaporation of a trace element. Thus $\mathrm{P}_{\mathrm{Zn}, \mathrm{sat}}$ can be expressed as:

$$
P_{Z n, s a t}=\gamma_{Z n O}\left(\frac{N_{Z n}^{0}-N_{Z n}^{g}}{N v}\right) \frac{P_{Z n O}^{*}}{K_{Z n O} P_{O}^{1 / 2}}
$$

where $N_{Z n}^{0}$ is the total number of moles of $Z n$ in the system, $P_{Z n, s a t}$ is the vapor pressure for species $\mathrm{ZnO}$ and $\gamma_{\mathrm{ZnO}}$ is the activity coefficient of $\mathrm{ZnO}$ in the solid. Thus, equation (62) can be expressed as a function of $N_{Z n}^{g}$ and the equation can be rewritten as

$$
\frac{d \mathrm{~N}_{Z n}^{g}}{d t}=\frac{4 \pi r^{2} \gamma_{i} C_{Z n}^{0}}{\sqrt{2 \pi m_{Z n} R T}}\left(\frac{P_{Z n O}^{*}}{K_{Z n O} P_{O_{2}}^{1 / 2}}\right)-\frac{\mathrm{N}_{Z n}^{g}}{\sqrt{2 \pi m_{Z n} R T}}\left(4 \pi r^{2} d_{N} R T+\frac{3}{r} \gamma_{Z n o}\left(\frac{P_{Z n O}^{*}}{K_{Z n O} P_{O_{2}}^{1 / 2}}\right)\right)
$$

This equation can be solved analytically with the following solution, assuming no initial $\mathrm{Zn}$ in the gas phase: 


$$
\mathrm{N}_{Z n}^{g}(t)=\frac{d_{N}}{K} \frac{4 \pi r^{2} \gamma_{i} C_{Z n}^{0}}{\sqrt{2 \pi m_{Z n} R T}}\left(\frac{P_{Z n O}^{*}}{K_{Z n O} P_{O_{2}}^{1 / 2}}\right)\left(1-e^{-K t}\right)
$$

where $\mathrm{K}$ is defined as:

$$
K=\frac{1}{\sqrt{2 \pi m_{Z n} R T}}\left(4 \pi r^{2} d_{N} R T+\frac{3}{r} \gamma_{Z n O}\left(\frac{P_{Z n O}^{*}}{K_{Z n O} P_{O_{2}}^{1 / 2}}\right)\right)
$$

It is worth pointing out that Alexander ${ }^{63}$ has also dealt with the dissociation of oxides upon vaporization, with a similar formalism in his PCR model (pure component reference model) and his EQR (equilibrium reference model), although it was not targeted at dealing with collective effects.

Our model shows that in this particular case, the vapor pressure controlling the evaporation rate decreases as the amount of element $i$ in the gas phase decreases until reaching a steady state value that depends on the initial amount of element $i$ in the condensed phase and how it gets diluted over the considered volume. Thus, the dynamics of evaporation evolves continuously unlike the case of a major element (e.g., $\mathrm{Mg}, \mathrm{Si}$, or Fe), where the concentration of the elements can be controlled by the stoichiometry of the condensed phase (e.g., $\mathrm{Mg}_{2} \mathrm{SiO}_{4}$ ) as is the case for congruent evaporation. If one were to model the case of chondrule formation, one would need to take into account the absence of stoichiometric control with a complex chondritic melt. For the sake of illustration, we have constructed the model curves showing the $\delta^{66} \mathrm{Zn}$ as a function of the evaporated fraction of $\mathrm{Zn}$ for various values of $\mathrm{d}_{\mathrm{N}}$, the main control parameter in this model (Figure 6). To illustrate the collective effect, the evaporation of $\mathrm{Zn}$ from an olivine was modeled (a single mineral is used for the sake of simplicity). The $\mathrm{O}_{2}$ partial pressure in equilibrium with olivine was taken from Costa et al. ${ }^{90}$ while the pressure of $\mathrm{ZnO}(\mathrm{g})$ for a pure $\mathrm{ZnO}$ vaporization and the value of $\mathrm{K}_{\mathrm{ZnO}}$ were obtained from Lamoreaux et al. ${ }^{91}$. 
Then, the isotope fractionation of $\mathrm{Zn}$ in the condensed phase was calculated assuming variable values of $d_{N}$, representing the density of olivine grains per unit volume. As expected, for a larger number of grains the vaporized fraction decreased and the total vapor pressure increased. The $\mathrm{Zn}$ isotope fractionation decreased with the vapor pressure and after reaching equilibrium the isotope fractionation was negligible. This effect shows the buffering due to collective evaporation (Figure 6). This situation could arise during chondrule formation in a dust-rich environment ${ }^{89}$ where the density of dust could range between 2 and $\sim 10,000 \mathrm{~g} / \mathrm{m}^{3}{ }^{92}$. Alexander ${ }^{61}$ has considered a closed system to model the elemental and isotopic evolution of chondrules and showed that Type A chondrules could have formed in equilibrium with a high solid/gas ratio (similar to what was modeled here). Initially vaporization could indeed lead to large $\mathrm{Zn}$ isotope fractionation but this would be rapidly dampened as $\mathrm{Zn}$ reach saturation. Thus, the isotope effects are consistent with the observed reduction in evaporation rate when considering a large population of evaporating drops ${ }^{88}$. This effect also seems consistent with observations of Mg isotope in chondrules that often reveal limited Mg isotope fractionation (e.g., ref $^{45}$ ).

\section{Isotope fractionation during evaporation with two isotope species}

In the treatment of isotope fractionation due to evaporation, it is generally considered that there is only one species evaporating that is responsible for isotope fractionation. However, thermodynamic modeling shows that in many cases, several species in the gas phase can coexist. This has been shown in numerous Knudsen effusion mass spectrometry experiments. In this case, since each species will be characterized by its own isotope fractionation factor, the pattern of isotope fractionation shall be more complex and we provide an example where this has been 
observed in the case of $\mathrm{Cr}$ evaporation. Several workers have attempted to model these effects, especially in the context of mass spectrometry measurements ${ }^{93,94}$. Kanno ${ }^{94}$ considered only the case of systems with only two isotopes such as $\mathrm{B}$ or $\mathrm{Li}$, which is a little restrictive. Habfast ${ }^{93}$ considered a more general case including dissociation of molecular species with numerous poorly constrained parameters. In our treatment we have chosen to deal with the case of multiple isotopes without considering the effect of dissociation that is difficult to constrain quantitatively. The HertzKnudsen equation can be written as follows for a single isotope species:

$$
\frac{d n i}{d t}=\frac{\gamma_{e} P_{i, s a t}-\gamma_{c} P_{i}}{\sqrt{2 \pi m i k T}}
$$

When there is more than one species evaporating then the equation needs to include additional terms for the other species. Let us assume there are two main species 1 and 2 , in which case the equation can be written:

$$
\frac{d n_{i}}{d t}=\frac{d n_{i}^{1}}{d t}+\frac{d n_{i}^{2}}{d t}=\frac{\gamma_{1}\left(P_{i, s a t}^{1}-P_{i}^{1}\right)}{\sqrt{2 \pi m_{i}^{1} k T}}+\frac{\gamma_{1}\left(P_{i, s a t}^{12}-P_{i}^{2}\right)}{\sqrt{2 \pi m_{i}^{2} k T}}
$$

This equation can be transformed as follows:

$$
\frac{d n_{i}}{d t}=\frac{\gamma_{1} P_{i, s a t}^{1}\left(1-P_{i}^{1} / P_{i, s a t}^{1}\right)}{\sqrt{2 \pi m_{i}^{1} k T}}+\frac{\gamma_{1} P_{i, s a t}^{2}\left(1-P_{i}^{2} / P_{i, s a t}^{2}\right)}{\sqrt{2 \pi m_{i}^{2} k T}}
$$

The quantity we are interested in is the variation in the ratio of isotope $\mathrm{i}$ to isotope $\mathrm{j}$ :

$$
\frac{d n_{i}}{d n_{j}}=\frac{\frac{\gamma_{i}^{1} P_{i, s a t}^{1}\left(1-P_{i}^{1} / P_{i, s a t}^{1}\right)}{\sqrt{2 \pi m_{i}^{1} k T}}+\frac{\gamma_{i}^{2} P_{i, s a t}^{2}\left(1-P_{i}^{2} / P_{i, s a t}^{2}\right)}{\sqrt{2 \pi m_{i}^{2} k T}}}{\sqrt{2 \pi m_{j}^{1} k T}}+\frac{\gamma_{j}^{2} P_{j, s a t}^{2}\left(1-P_{j}^{2} / P_{j, s a t}^{2}\right)}{\sqrt{2 \pi m_{j}^{2} k T}}
$$

The isotope equilibrium fractionation factor for both species 1 and 2 can be written: 
$\alpha_{e q}^{1}=\frac{n_{i} / n_{j}}{P_{i, s a t}^{1} / P_{j, s a t}^{1}} \quad$ and $\quad \alpha_{e q}^{2}=\frac{n_{i} / n_{j}}{P_{i, s a t}^{2} / P_{j, s a t}^{2}}$

Thus, the equation can be simplified to:

$$
\frac{d n_{i}}{d n_{j}}=\frac{\frac{\gamma_{i}^{1} n_{i} / n_{j} P_{j, s a t}^{1} / \alpha_{e q}^{1}\left(1-P_{i}^{1} / P_{i, s a t}^{1}\right)}{\sqrt{2 \pi m_{i}^{1} k T}}+\frac{\gamma_{i}^{2} n_{i} / n_{j} P_{j, s a t}^{2} / \alpha_{e q}^{2}\left(1-P_{i}^{2} / P_{i, s a t}^{2}\right)}{\sqrt{2 \pi m_{i}^{2} k T}}}{\frac{\gamma_{j}^{1} P_{j, s a t}^{1}\left(1-P_{j}^{1} / P_{j, s a t}^{1}\right)}{\sqrt{2 \pi m_{j}^{1} k T}}+\frac{\gamma_{j}^{2} P_{j, s a t}^{2}\left(1-P_{j}^{2} / P_{j, s a t}^{2}\right)}{\sqrt{2 \pi m_{j}^{2} k T}}}
$$

We now make the hypothesis that the ratio of vapor pressures for the two species 1 and 2 is a function that depends only on temperature:

$$
\frac{P_{j, s a t}^{2}}{P_{j, s a t}^{1}}=k(T)
$$

In this case, the above equation can be simplified to:

$$
\frac{d n_{i}}{d n_{j}}=\frac{n_{i}}{n_{j}} \frac{\frac{\gamma_{i}^{1} / \alpha_{e q}^{1}\left(1-P_{i}^{1} / P_{i, s a t}^{1}\right)}{\sqrt{2 \pi m_{i}^{1} k T}}+\frac{\gamma_{i}^{2} k(T) / \alpha_{e q}^{2}\left(1-P_{i}^{2} / P_{i, s a t}^{2}\right)}{\sqrt{2 \pi m_{i}^{2} k T}}}{\sqrt{2 \pi m_{j}^{1} k T}}+\frac{\gamma_{j}^{1}\left(1-P_{j}^{1} / P_{j, s a t}^{1}\right)}{\sqrt{2 \pi m_{j}^{2} k T}}
$$

It is reasonable to make the approximation that:

$$
\left(1-P_{j}^{1} / P_{j, s a t}^{1}\right) \approx\left(1-\frac{P_{i}^{1}}{P_{i, s a t}^{1}}\right)
$$

Thus, equation 80 can be rewritten:

$$
\frac{d n_{i}}{d n_{j}}=\beta \frac{n_{i}}{n_{j}}
$$


where:

$$
\beta=\frac{\frac{\gamma_{i}^{1} / \alpha_{e q}^{1}\left(1-P_{j}^{1} / P_{j, s a t}^{1}\right)}{\sqrt{2 \pi m_{i}^{1} k T}}+\frac{\gamma_{i}^{2} k(T) / \alpha_{e q}^{2}\left(1-P_{j}^{2} / P_{j, s a t}^{2}\right)}{\sqrt{2 \pi m_{i}^{2} k T}}}{\frac{\gamma_{j}^{1}\left(1-P_{j}^{1} / P_{j, s a t}^{1}\right)}{\sqrt{2 \pi m_{j}^{1} k T}}+\frac{\gamma_{j}^{2} k(T)\left(1-P_{j}^{2} / P_{j, s a t}^{2}\right)}{\sqrt{2 \pi m_{j}^{2} k T}}}
$$

This equation can easily be solved for $n_{i} / n_{j}$ :

$$
\frac{n_{i}}{n_{j}}=\frac{n_{i}^{0}}{n_{j}^{0}}\left(\frac{n_{j}}{n_{j}^{0}}\right)^{\beta-1}
$$

The instantaneous composition of the vapor for species 1 can then be written directly:

$$
\frac{d n_{i}^{1}}{d n_{j}^{1}}=\frac{\frac{\gamma_{1} P_{i, s a t}^{1}\left(1-P_{i}^{1} / P_{i, s a t}^{1}\right)}{\sqrt{2 \pi m_{i}^{1} k T}}}{\frac{\gamma_{1} P_{j, s a t}^{1}\left(1-P_{j}^{1} / P_{j, s a t}^{1}\right)}{\sqrt{2 \pi m_{i}^{1} k T}}}
$$

The variation of isotope ratios for species 1 can be written:

$$
r_{i_{-j}}^{1}=\frac{d n_{i}^{1}}{d n_{j}^{1}}=\frac{1}{\alpha_{\text {evap }}^{1}} \frac{n_{i}}{n_{j}}
$$

where the expression for $\alpha_{\text {evap }}^{1}$ is, using the approach outlined in section 3.2:

$$
\alpha_{\text {evap }}^{1}=\frac{\left(1-P_{j}^{1} / P_{j, \text { sat }}^{1}\right)+\gamma_{i}^{1} / \gamma_{j}^{1} \alpha_{\text {kin }}\left(P_{j}^{1} / P_{j, s a t}^{1}\right)}{\gamma_{i}^{1} / \gamma_{j}^{1} \alpha_{k i n} / \alpha_{e q}^{1}}
$$

By integrating equation 86 , it is possible to determine the isotope fractionation of species 1 when there are two species evaporating. Equation 80 can easily be generalized to $n$ species, if there are more than two evaporating species. In what follows, the effect of having more than one species evaporating is explored in the case of $\mathrm{Cr}$ isotope measurements by thermal ionization mass spectrometry (TIMS), and the model developed above shows that there are unusual isotope fractionation patterns in this case. 
The analysis of $\mathrm{Cr}$ isotopes by TIMS represents an evaporation experiment where $\mathrm{Cr}$ is evaporated from a silicate glass matrix. The activator used to enhance $\mathrm{Cr}^{+}$emission is a mixture of silica gel, aluminum nitrate solution and boric acid ${ }^{95}$. This activator is deposited onto a $\operatorname{Re}$ or W filament and outgassed briefly. Thus, the $\mathrm{Cr}$ is incorporated in an alumino-silicate matrix doped with boron. An experimental study of such a Cr load heated under vacuum (typical source pressure is $10^{-8}$ mbar) shows that there is emission of $\mathrm{Cr}^{+}, \mathrm{CrO}^{+}$and minor $\mathrm{CrO}^{2+}$. Given differences in ionization potentials, $\left(\mathrm{IP}(\mathrm{Cr})=7 \mathrm{eV}, \mathrm{IP}(\mathrm{CrO})=7.7 \mathrm{eV}, \mathrm{IP}\left(\mathrm{CrO}_{2}\right)=10.4 \mathrm{eV}\right)$ the observed $\mathrm{Cr}^{+}, \mathrm{CrO}^{+}$ and $\mathrm{CrO}^{2+}$ signals are not directly representative of the $\mathrm{Cr}, \mathrm{CrO}$, and $\mathrm{CrO}_{2}$ evaporation fluxes. As shown in Figure 7, at high temperatures, the $\mathrm{CrO}^{+} / \mathrm{Cr}^{+}$signal increases up to a temperature of $1500^{\circ} \mathrm{C}$. The ratio of vapor pressures $\mathrm{P}_{\mathrm{CrO}(\mathrm{g}) / \mathrm{P}_{\mathrm{Cr}(\mathrm{g})} \text { calculated with the FACTSAGE }}{ }^{\mathrm{TM}}$ software for the $\mathrm{Cr}$-Al-Si-B-O composition used in loading also increases between 1200 and $1500^{\circ} \mathrm{C}$, indicating a significant $\mathrm{Cr}$ oxide component in the vapor phase. Using the calculated partial pressures and the ionization potentials, it is possible to recalculate the corresponding $\mathrm{CrO}^{+} / \mathrm{Cr}^{+}$ratios, and the results are overall consistent with the thermodynamic calculations (Figure 7).

If one assumes that the isotope fractionation during analysis is controlled by evaporation, it is possible to calculate the instantaneous isotope ratio in the vapor over the course of an analysis. For the sake of simplification, we shall assume that the equilibrium isotope fractionation factor is equal to 1 during $\mathrm{Cr}$ oxide and $\mathrm{Cr}$ metal vaporization and that the local partial pressure in $\mathrm{Cr}, \mathrm{CrO}$ and $\mathrm{CrO}_{2}$ is negligible relative to the vapor pressure. In this case, the isotope fractionation factor given in equation 81 is equal to: 


$$
\beta=\frac{\frac{1}{\sqrt{2 \pi m_{i}^{1} k T}}+\frac{k(T)}{\sqrt{2 \pi m_{i}^{2} k T}}}{\frac{1}{\sqrt{2 \pi m_{j}^{1} k T}}+\frac{k(T)}{\sqrt{2 \pi m_{j}^{2} k T}}}=\frac{\frac{1}{\sqrt{m_{i}^{1}}}+\frac{k(T)}{\sqrt{m_{i}^{2}}}}{\frac{1}{\sqrt{m_{j}^{1}}}+\frac{k(T)}{\sqrt{m_{j}^{2}}}}
$$

In this case, the expression for the isotope ratios for $\mathrm{Cr}$ can be simply written as:

$$
\frac{r_{i j}}{r_{i j}^{T}}=\alpha\left(\frac{n_{j}}{n_{j}^{0}}\right)^{\alpha-1}
$$

where $\mathrm{r}_{\mathrm{ij}}$ and $r_{i j}^{T}$ represent the measured and true isotope ratios, respectively. If the $\mathrm{Cr}$ isotope ratios are normalized to a given value of the reference isotope ratio, then the isotope ratios corrected for mass fractionation using the exponential law are:

$$
\frac{r_{i j}}{R_{i j}}=\left(\frac{m_{i}}{m_{j}}\right)^{\gamma}
$$

where $\gamma$ is a fractionation factor and $\mathrm{R}_{\mathrm{ij}}$ represents the corrected (in principle true) ratio. If the isotope ratios have been fractionated due to the presence of two or three evaporating species, then the isotope fractionation pattern is slightly different from what it is if a single species evaporates. Thus, the correction induces a deviation from the true ratio and the offset depends directly on the ratio of $\mathrm{CrO}$ to $\mathrm{Cr}$ in the vapor, $\mathrm{k}(\mathrm{T})$. Using a series of measured $\mathrm{Cr}$ isotope standards run at a temperature of $1300^{\circ} \mathrm{C}$ approximately using the procedure described in ${ }^{95}$, one observes, after mass fractionation correction using the exponential law and a reference value for the ${ }^{50} \mathrm{Cr} /{ }^{52} \mathrm{Cr}$ ratio, that there is a residual trend in the ${ }^{54} \mathrm{Cr} /{ }^{52} \mathrm{Cr}$ versus ${ }^{53} \mathrm{Cr} /{ }^{52} \mathrm{Cr}$ diagram (Figure 8). Using the formalism derived above, it is possible to calculate the variations in corrected $\mathrm{Cr}$ isotope ratios obtained for the measured range of $\mathrm{k}(\mathrm{T})$ (Figure 8). The calculated variations match the observed range in 
${ }^{54} \mathrm{Cr} /{ }^{52} \mathrm{Cr}$ and ${ }^{53} \mathrm{Cr} /{ }^{52} \mathrm{Cr}$ ratios. Thus, the measured $\mathrm{CrO}^{+} / \mathrm{Cr}^{+}$and the predicted $\mathrm{Cr}$ speciation are consistent with the proposed fractionation law with two or three vapor species. Our observations may explain that in some cases, the exponential law by itself does not properly correct instrumental fractionation, leading to residual variations after mass fractionation correction. This could be the case of high precision ${ }^{142} \mathrm{Nd}$ TIMS analysis where both $\mathrm{Nd}$ and $\mathrm{NdO}$ are observed. Similar considerations we made by Caro et al. ${ }^{96}$ who showed that when normalizing $\mathrm{Nd}$ isotopes to a standard ratio could lead to residual correlations in a diagram showing isotope ratios corrected for mass fractionation (see also ref ${ }^{97}$ ). This situation could also take place in natural settings with two or more evaporating species, in which case there could be deviations in isotope ratios after normalization to a given isotope ratio.

\section{Conclusions.}

While there is abundant literature focusing on evaporation and condensation of solids and liquids, there is far less information about isotope fractionation associated with these processes, in particular with respect to geologically relevant materials. As high precision isotope data accumulate on volatile and refractory elements, it will become relevant to have a better understanding of the controls of isotope fractionation linked with evaporation/condensation in the early Solar System.

Our study shows that a better knowledge of evaporation coefficients would be extremely helpful to model more accurately the thermodynamical conditions of evaporation or condensation. The evaporation coefficients that are a function of the energetic barrier to evaporation depend directly on chemical composition and temperature. A smaller evaporation coefficient seems associated with greater isotope fractionation. Given their similarity with kinetic isotope fractionation factors, 
the ratio of evaporation coefficients should go to 1 at infinite temperature. We also have illustrated that several kinetic parameters control the overall isotope fractionation during evaporation: kinetic fractionation due to diffusion, kinetic fractionation linked with the evaporation itself and kinetics of detachment from the surface.

Second, we have reemphasized the fact that evaporation or condensation operates with an ambient pressure and that this tends to limit isotope fractionation. Being able to precisely model the local pressure near a reactive surface will be a challenge for future studies. As the purely diffusive case has already been modeled successfully, it may be more desirable to include an advective component.

Our study also illustrates that the pattern of fractionation need not be always described by a simple Rayleigh fractionation. Rather, we show there are many different patterns of isotope fractionation associated with evaporation or condensation and that these patterns may be used as a diagnostic for the type of process. This study has extended the number of models in particular with respect to closed system evolution. Furthermore we have shown that the effective isotope fractionation factor may be different from the classical used kinetic isotope fractionation factor. Our modeling approach is probably simplistic compared with real cases and should be considered as illustrative.

\section{FIGURES}

Figure 1. The relationship between the ratio of evaporation coefficients, $\gamma^{30}{ }_{S i} / \gamma^{28}{ }_{S i}$ and bond lengths for silicates. Data source: Knight et al. ${ }^{72}$; Davis et al. ${ }^{17}$; Wang et al. ${ }^{19}$. The longer bond length correspond to a smaller energetic barrier to evaporation, associated with a weaker $\mathrm{Si}$ isotope fractionation. References for bond lengths are Haring ${ }^{98}$ and Guillot and Sator ${ }^{99}$. 
Figure 2. $\mathrm{Mg}$ isotope fractionation factor for Type B CAI-like material, determined experimentally plotted as a function of temperature showing a convergence towards the theoretical kinetic isotope fractionation factor $\sqrt{24 / 26}$ at high temperature, as predicted with equation (16). Data source compiled by Richter et al. ${ }^{21}$.

Figure 3. Theoretical curves in a $\delta^{66} \mathrm{Zn}$ versus fraction condensed, showing the effect of condensation in a finite volume in the case of $\mathrm{Zn}$ isotopes. The curves are labeled with the initial degree of oversaturation as defined in main text. $\delta^{66} \mathrm{Zn}$ is defined as $\left(\left({ }^{66} \mathrm{Zn} /{ }^{64} \mathrm{Zn}\right)_{\text {sample }} /\left({ }^{66} \mathrm{Zn} /{ }^{64} \mathrm{Zn}\right)_{\text {std }}-1\right) \times 1000$ in \%o. Note that the shapes of these model curves differ markedly from the classical Rayleigh curves for condensation.

Figure 4. $\mathrm{Zn}$ isotope variations in ordinary chondrites (data from Luck et al. ${ }^{26}$ ). A best-fit model curve obtained with a condensation model in a finite volume is also shown, using the equations in section $4(\beta=0.85)$.

Figure 5. Theoretical curve showing the pattern of $\mathrm{Mg}$ isotope fractionation as a function of $\mathrm{Mg}$ depletion for evaporation in a finite volume. The $\mathrm{Mg}$ isotope fractionation factor decreases as 
saturation increases, which yields a concave shape for the model curves. The model curves are calculated for various values of the undersaturation defined as $\mathrm{P}_{\mathrm{i}, 0} / \mathrm{P}_{\mathrm{i}, \text { sat }}$ as labeled on the curves.

Figure 6. Diagram showing model curves for $\delta^{66} \mathrm{Zn}$ (where ${ }^{64} \mathrm{Zn}$ is used in the denominator) in the condensed phases during closed system evaporation from a collection of olivine spheres in a fixed volume. The temperature of vaporization was $2000 \mathrm{~K}$. The density of grains per cubic meter is labeled on the model curves. The initial $\mathrm{Zn}$ concentration was $300 \mathrm{ppm}$ and the initial radius of each grain was $1 \mathrm{~mm}$.

Figure 7. (a) Predicted $\mathrm{P}_{\mathrm{CrO}} / \mathrm{P}_{\mathrm{Cr}}$ in the vapor during emission from a TIMS filament with an $\mathrm{SiO}_{2}$, $\mathrm{B}_{2} \mathrm{O}_{3}$ and $\mathrm{Al}_{2} \mathrm{O}_{3}$ activator. (b) Comparison between the predicted and the observed $\mathrm{CrO}^{+} / \mathrm{Cr}^{+}$ during TIMS emission. The assumed ionization potentials for $\mathrm{CrO}$ and $\mathrm{Cr}$ are 6.8 and $7.7 \mathrm{eV}$ respectively.

Figure 8. Cr isotope composition of NIST SRM 979 standards reported as $\mu^{53} \mathrm{Cr}$ versus $\mu^{54} \mathrm{Cr}$ using ${ }^{52} \mathrm{Cr} /{ }^{50} \mathrm{Cr}$ as a normalizing ratio. All the data was measured with a TRITON TIMS using the procedure described in ref. ${ }^{95}$ and corrected with the exponential law. The red circle represents individual $\mathrm{Cr}$ standard measurements and the solid line is the predicted trend using the fractionation law involving two evaporating species (see text for details). 


\section{ASSOCIATED CONTENT}

\section{Supporting Information.}

Cr isotope standard measured by TIMS: Cr_standards.pdf (PDF)

\section{AUTHOR INFORMATION}

\section{Corresponding Author}

*Bernard Bourdon bernard.bourdon@ens-lyon.fr

\section{Author Contributions}

The manuscript was written through contributions of all authors. All authors have given approval to the final version of the manuscript.

\section{Funding Sources}

This study was funded by the ERC Advanced Grant COSMOKEMS \# 694819.

\section{ACKNOWLEDGMENTS}

Discussions with Dmitry Ivanov, Christian Chatillon and Armand Gabriel are acknowledged. Mélie Cornet is thanked for providing the $\mathrm{Cr}$ isotope measurements of the standards. This manuscript was greatly improved by the comments made by $\mathrm{C}$. Alexander and two anonymous reviewers. The authors declare no competing financial interest. 


\section{REFERENCES}

(1) Halliday, A. N.; Porcelli, D. In Search of Lost Planets - The Paleocosmochemistry of the Inner Solar System. Earth Planet. Sci. Lett. 2001, 192 (4), 545-559. https://doi.org/10.1016/S0012-821X(01)00479-4.

(2) Taylor, G. J. The Bulk Composition of Mars. Chemie der Erde. Elsevier GmbH December 1, 2013, pp 401-420. https://doi.org/10.1016/j.chemer.2013.09.006.

(3) Prettyman, T. H.; Yamashita, N.; Reedy, R. C.; McSween, H. Y.; Mittlefehldt, D. W.; Hendricks, J. S.; Toplis, M. J. Concentrations of Potassium and Thorium within Vesta's Regolith. Icarus 2015, 259, 39-52. https://doi.org/10.1016/j.icarus.2015.05.035.

(4) Peplowski, P. N.; Evans, L. G.; Hauck, S. A.; McCoy, T. J.; Boynton, W. V.; Gillis-Davis, J. J.; Ebel, D. S.; Goldsten, J. O.; Hamara, D. K.; Lawrence, D. J.; et al. Radioactive Elements on Mercury's Surface from MESSENGER: Implications for the Planet's Formation and Evolution. Science (80-. ). 2011, 333 (6051), 1850-1852. https://doi.org/10.1126/science.1211576.

(5) Palme, H.; Hutchison, R. Chemical and Isotopic Heterogeneity in Protosolar Matter. Philos. Trans. R. Soc. A Math. Phys. Eng. Sci. 2001, 359 (1787), 2061-2075. https://doi.org/10.1098/rsta.2001.0897.

(6) Yin, Q. From Dust to Planets: The Tale Told by Moderately Volatile Elements. In Chondrites and the Protoplanetary Disk; 2005; Vol. 341, p 632.

(7) Cassen, P. Models for the Fractionation of Moderately Volatile Elements in the Solar Nebula. Meteorit. Planet. Sci. 1996, 31 (6), 793-806. https://doi.org/10.1111/j.1945- 
5100.1996.tb02114.x.

(8) Ciesla, F. J. Radial Transport in the Solar Nebula: Implications for Moderately Volatile Element Depletions in Chondritic Meteorites. Meteorit. Planet. Sci. 2008, 43 (4), 639-655. https://doi.org/10.1111/j.1945-5100.2008.tb00675.x.

(9) Hewins, R. H.; Radomsky, P. M. Temperature Conditions for Chondrule Formation. Meteoritics 1990, 25 (4), 309-318. https://doi.org/10.1111/j.1945-5100.1990.tb00715.x.

(10) Bland, P. A.; Alard, O.; Benedix, G. K.; Kearsley, A. T.; Menzies, O. N.; Watt, L. E.; Rogers, N. W. Volatile Fractionation in the Early Solar System and Chondrule/Matrix Complementarity. Proc. Natl. Acad. Sci. U. S. A. 2005, 102 (39), 13755-13760. https://doi.org/10.1073/pnas.0501885102.

(11) Ebel, D. S.; Alexander, C. M. O. D.; Libourel, G. Vapor-Melt Exchange: Constraints on Chondrite Formation Conditions and Processes; Russell, S. S., Connolly Jr., H. C., Krot, A. N., Eds.; Cambridge University Press, 2018; pp 151-174.

(12) Schaefer, L.; Fegley, B. Volatile Element Chemistry during Metamorphism of Ordinary Chondritic Material and Some of Its Implications for the Composition of Asteroids. Icarus 2010, 205 (2), 483-496. https://doi.org/10.1016/j.icarus.2009.08.025.

(13) Kato, C.; Moynier, F.; Valdes, M. C.; Dhaliwal, J. K.; Day, J. M. D. Extensive Volatile Loss during Formation and Differentiation of the Moon. Nat. Commun. 2015, 6. https://doi.org/10.1038/ncomms8617.

(14) Dhaliwal, J. K.; Day, J. M. D.; Moynier, F. Volatile Element Loss during Planetary Magma Ocean Phases. Icarus 2018, 300, 249-260. https://doi.org/10.1016/j.icarus.2017.09.002. 
(15) Hin, R.; Coath, C.; Carter, P.; Nimmo, F.; Lai, Y.-J.; Pogge von Strandmann, P. A. E.; Willbold, M.; Leinhardt, Z. M.; Walter, M. J.; Elliott, T. Magnesium Isotope Evidence That Accretional Vapour Loss Shapes Planetary Compositions. Nature 549, 511-515.

(16) Young, E. D.; Shahar, A.; Nimmo, F.; Schlichting, H. E.; Schauble, E. A.; Tang, H.; Labidi, J. Near-Equilibrium Isotope Fractionation during Planetesimal Evaporation. Icarus 2019, 323, 1-15. https://doi.org/10.1016/j.icarus.2019.01.012.

(17) Davis, A. M.; Hashimoto, A.; Clayton, R. N.; Mayeda, T. K. Isotope Mass Fractionation during Evaporation of Mg2Si04. Nature 1990, 347 (6294), 655-658. https://doi.org/10.1038/347655a0.

(18) Wang, J.; Davis, A. M.; Clayton, R. N.; Hashimoto, A. Evaporation of Single Crystal Forsterite: Evaporation Kinetics, Magnesium Isotope Fractionation, and Implications of Mass-Dependent Isotopic Fractionation of a Diffusion-Controlled Reservoir. Geochim. Cosmochim. Acta 1999, 63 (6), 953-966. https://doi.org/10.1016/S0016-7037(98)00286-5.

(19) Wang, J.; Davis, A. M.; Clayton, R. N.; Mayeda, T. K.; Hashimoto, A. Chemical and Isotopic Fractionation during the Evaporation of the FeO-MgO-SiO2-CaO-A12O3-TiO2 Rare Earth Element Melt System. Geochim. Cosmochim. Acta 2001, 65 (3), 479-494. https://doi.org/10.1016/S0016-7037(00)00529-9.

(20) Richter, F. M.; Davis, A. M.; Ebel, D. S.; Hashimoto, A. Elemental and Isotopic Fractionation of Type B Calcium-, Aluminum-Rich Inclusions: Experiments, Theoretical Considerations, and Constraints on Their Thermal Evolution. Geochim. Cosmochim. Acta 2002, 66 (3), 521-540. https://doi.org/10.1016/S0016-7037(01)00782-7. 
(21) Richter, F. M.; Janney, P. E.; Mendybaev, R. A.; Davis, A. M.; Wadhwa, M. Elemental and Isotopic Fractionation of Type B CAI-like Liquids by Evaporation. Geochim. Cosmochim. Acta 2007, 71 (22), 5544-5564. https://doi.org/10.1016/j.gca.2007.09.005.

(22) Richter, F. M.; Mendybaev, R. A.; Christensen, J. N.; Ebel, D.; Gaffney, A. Laboratory Experiments Bearing on the Origin and Evolution of Olivine-Rich Chondrules. Meteorit. Planet. Sci. 2011, 46 (8), 1152-1178. https://doi.org/10.1111/j.1945-5100.2011.01220.x.

(23) Zhang, J.; Huang, S.; Davis, A. M.; Dauphas, N.; Hashimoto, A.; Jacobsen, S. B. Calcium and Titanium Isotopic Fractionations during Evaporation. Geochim. Cosmochim. Acta 2014, 140, 365-380. https://doi.org/10.1016/j.gca.2014.05.022.

(24) Humayun, M.; Clayton, R. N. Potassium Isotope Cosmochemistry: Genetic Implications of Volatile Element Depletion. Geochim. Cosmochim. Acta 1995, 59 (10), 2131-2148. https://doi.org/10.1016/0016-7037(95)00132-8.

(25) Shahar, A.; Young, E. D. Astrophysics of CAI Formation as Revealed by Silicon Isotope LA-MC-ICPMS of an Igneous CAI. Earth Planet. Sci. Lett. 2007, 257 (3-4), 497-510. https://doi.org/10.1016/j.epsl.2007.03.012.

(26) Luck, J. M.; Othman, D. Ben; Albarède, F. Zn and Cu Isotopic Variations in Chondrites and Iron Meteorites: Early Solar Nebula Reservoirs and Parent-Body Processes. Geochim. Cosmochim. Acta 2005, 69 (22), 5351-5363. https://doi.org/10.1016/j.gca.2005.06.018.

(27) Varas-Reus, M. I.; König, S.; Yierpan, A.; Lorand, J. P.; Schoenberg, R. Selenium Isotopes as Tracers of a Late Volatile Contribution to Earth from the Outer Solar System. Nat. Geosci. 2019, 12 (9), 779-782. https://doi.org/10.1038/s41561-019-0414-7. 
(28) Pringle, E. A.; Moynier, F.; Beck, P.; Paniello, R.; Hezel, D. C. The Origin of Volatile Element Depletion in Early Solar System Material: Clues from Zn Isotopes in Chondrules. Earth Planet. Sci. Lett. 2017, 468, 62-71. https://doi.org/10.1016/j.eps1.2017.04.002.

(29) Vollstaedt, H.; Mezger, K.; Leya, I. The Isotope Composition of Selenium in Chondrites Constrains the Depletion Mechanism of Volatile Elements in Solar System Materials. Earth Planet. Sci. Lett. 2016, 450, 372-380. https://doi.org/10.1016/j.eps1.2016.06.052.

(30) Wang, K.; Jacobsen, S. B. Potassium Isotopic Evidence for the Origin of the Moon. Submitt. to Nat. 2016, 1-10.

(31) Bloom, H.; Lodders, K.; Chen, H.; Zhao, C.; Tian, Z.; Koefoed, P.; Pető, M. K.; Jiang, Y.; Wang (王昆), K. Potassium Isotope Compositions of Carbonaceous and Ordinary Chondrites: Implications on the Origin of Volatile Depletion in the Early Solar System. Geochim. $\quad$ Cosmochim. $\quad$ Acta $\quad \mathbf{2 0 2 0}, \quad 277, \quad 111-131$. https://doi.org/10.1016/j.gca.2020.03.018.

(32) Fitoussi, C.; Bourdon, B.; Kleine, T.; Oberli, F.; Reynolds, B. C. Si Isotope Systematics of Meteorites and Terrestrial Peridotites: Implications for $\mathrm{Mg} / \mathrm{Si}$ Fractionation in the Solar Nebula and for Si in the Earth's Core. Earth Planet. Sci. Lett. 2009, 287 (1-2), 77-85. https://doi.org/10.1016/j.eps1.2009.07.038.

(33) Ozawa, K.; Nagahara, H. Chemical and Isotopic Fractionations by Evaporation and Their Cosmochemical Implications. Geochim. Cosmochim. Acta 2001, 65 (13), 2171-2199. https://doi.org/10.1016/S0016-7037(01)00578-6.

(34) Nagahara, H.; Ozawa, K. Evaporation of Forsterite in H2 Gas. Geochim. Cosmochim. Acta 
1996, 60 (8), 1445-1459. https://doi.org/10.1016/0016-7037(96)00014-2.

(35) Labidi, J.; König, S.; Kurzawa, T.; Yierpan, A.; Schoenberg, R. The Selenium Isotopic Variations in Chondrites Are Mass-Dependent; Implications for Sulfide Formation in the Early Solar System. Earth Planet. Sci. Lett. 2018, 481, 212-222. https://doi.org/10.1016/j.eps1.2017.10.032.

(36) Young, E. D.; Nagahara, H.; Mysen, B. O.; Audet, D. M. Non-Rayleigh Oxygen Isotope Fractionation by Mineral Evaporation: Theory and Experiments in the System SiO2. Geochim. Cosmochim. Acta 1998, 62 (18), 3109-3116. https://doi.org/10.1016/S00167037(98)00213-0.

(37) Young, E. D. Assessing the Implications of K Isotope Cosmochemistry for Evaporation in the Preplanetary Solar Nebula. Earth Planet. Sci. Lett. 2000, 183 (1-2), 321-333. https://doi.org/10.1016/S0012-821X(00)00276-4.

(38) Nagahara, H.; Ozawa, K. Isotopic Fractionation as a Probe of Heating Processes in the Solar Nebula. Chem. Geol. 2000, 169 (1-2), 45-68. https://doi.org/10.1016/S00092541(99)00230-2.

(39) Davis, A. M.; Richter, F. M. Condensation and Evaporation of Solar System Materials. In Treatise on Geochemistry: Second Edition; Holland, H. D., Turekian, K. K., Eds.; Elsevier Inc., 2013; Vol. 1, pp 335-360. https://doi.org/10.1016/B978-0-08-095975-7.00112-1.

(40) Jouzel, J.; Merlivat, L. Deuterium and Oxygen 18 in Precipitation: Modeling of the Isotopic Effects during Snow Formation. J. Geophys. Res. 1984, 89 (D7). https://doi.org/10.1029/jd089id07p11749. 
(41) Simon, J. I.; DePaolo, D. J. Stable Calcium Isotopic Composition of Meteorites and Rocky Planets. Earth Planet. Sci. Lett. 2010, 289 (3-4), 457-466. https://doi.org/10.1016/j.eps1.2009.11.035.

(42) Dauphas, N.; Poitrasson, F.; Burkhardt, C.; Kobayashi, H.; Kurosawa, K. Planetary and Meteoritic $\mathrm{Mg} / \mathrm{Si}$ and $\Delta 30 \mathrm{Si}$ Variations Inherited from Solar Nebula Chemistry. Earth Planet. Sci. Lett. 2015, 427, 236-248. https://doi.org/10.1016/j.eps1.2015.07.008.

(43) Humayun, M.; Cassen, P. Processes Determining the Volatile Abundances of the Meteorites and Terrestrial Planets. Orig. Earth Moon 2000, 1, 3-23.

(44) Davis, A. M. Volatile Evolution and Loss. In Meteorites and the Early Solar System II; Lauretta, D. S., McSween Jr., H. Y., Eds.; University of Arizona Press, 2006; pp 295-307.

(45) Galy, A.; Young, E. D.; Ash, R. D.; O’Nions, R. K. The Formation of Chondrules at High Gas Pressures in the Solar Nebula. Science (80-. ). 2000, 290 (5497), 1751-1753. https://doi.org/10.1126/science.290.5497.1751.

(46) Alexander, C. M. O.; Grossman, J. N.; Wang, J.; Zanda, B.; Bourot-Denise, M.; Hewins, R. H. The Lack of Potassium-Isotopic Fractionation in Bishunpur Chondrules. Meteorit. Planet. Sci. 2000, 35 (4), 859-868. https://doi.org/10.1111/j.1945-5100.2000.tb01469.x.

(47) Alexander, C. M. O. D. Quantitative Models for the Elemental and Isotopic Fractionations in Chondrites: The Carbonaceous Chondrites. Geochim. Cosmochim. Acta 2019, 254, $277-$ 309. https://doi.org/10.1016/j.gca.2019.02.008.

(48) Wang, X.; Fitoussi, C.; Bourdon, B.; Fegley, B.; Charnoz, S. Tin Isotopes Indicative of Liquid-Vapour Equilibration and Separation in the Moon-Forming Disk. Nat. Geosci. 2019, 
12 (9), 707-711. https://doi.org/10.1038/s41561-019-0433-4.

(49) Nie, N. X.; Dauphas, N. Vapor Drainage in the Protolunar Disk as the Cause for the Depletion in Volatile Elements of the Moon. Astrophys. J. 2019, 884 (2), L48. https://doi.org/10.3847/2041-8213/ab4a16.

(50) Nagayama, G.; Takematsu, M.; Mizuguchi, H.; Tsuruta, T. Molecular Dynamics Study on Condensation/Evaporation Coefficients of Chain Molecules at Liquid-Vapor Interface. $J$. Chem. Phys. 2015, 143 (1). https://doi.org/10.1063/1.4923261.

(51) Persad, A. H.; Ward, C. A. Expressions for the Evaporation and Condensation Coefficients in the Hertz-Knudsen Relation. Chemical Reviews. American Chemical Society July 27, 2016, pp 7727-7767. https://doi.org/10.1021/acs.chemrev.5b00511.

(52) Gerasimov, D. N.; Yurin, E. I. Kinetics of Evaporation; Springer, 2018; Vol. 68. https://doi.org/10.1007/978-3-319-96304-4.

(53) Mortensen, E. M.; Eyring, H. Transmission Coefficients for Evaporation and Condensation. J. Phys. Chem. 1960, 64 (7), 846-849. https://doi.org/10.1021/j100836a004.

(54) Eyring, H.; Wanlass, F. H.; Eyring, E. M. Condensation and Vaporization of Condensed Phases. In Condensation and evaporiation of solids; Rutner, E., Goldfinger, P., Hirth, J. P., Eds.; Gordon and Breach, 1964; pp 4-57.

(55) Mulliken, R. S.; Harkins, W. D. The Separation of Isotopes. Theory of Resolution of Isotopic Mixtures by Diffusion and Similar Processes. Experimental Separation of Mercury by Evaporation in a Vacuum. $J$. Am. Chem. Soc. 1922, 44 (1), 37-65. https://doi.org/10.1021/ja01422a006. 
(56) Hirth, J. P.; Pound, G. M. Evaporation of Metal Crystals. J. Chem. Phys. 1957, 26 (5), 12161224. https://doi.org/10.1063/1.1743496.

(57) Paul, B. Compilation of Evaporation Coefficients. ARS J. 1962, 32 (9), 1321-1328. https://doi.org/10.2514/8.6277.

(58) Kagan, D.; Krechetova, G.; Fomin, I.; Shpilrain, E. Accommodation Coefficients of Liquid Metals Determined by the Langmuir Method with the Use of Electron Bombardment of a Skull Crucible. High Temp. - High Press. 2000, 32 (1), 115-121. https://doi.org/10.1068/htwu117.

(59) Sata, T.; Lee, H. L. Vacuum Vaporization in the System MgO-Cr2O3. J. Am. Ceram. Soc. 1978, 61 (7-8), 326-329. https://doi.org/10.1111/j.1151-2916.1978.tb09320.x.

(60) Shornikov, S. I. Vaporization Coefficients of Oxides Contained in the Melts of Ca-AlInclusions in Chondrites. Geochemistry Int. 2015, 53 (12), 1080-1089. https://doi.org/10.1134/S0016702915100055.

(61) Fedkin, A. V.; Grossman, L.; Ghiorso, M. S. Vapor Pressures and Evaporation Coefficients for Melts of Ferromagnesian Chondrule-like Compositions. Geochim. Cosmochim. Acta 2006, 70 (1), 206-223. https://doi.org/10.1016/j.gca.2005.08.014.

(62) Shornikov, S. Mass Spectrometric Study of Vaporization and Thermodynamic Properties of Silicon Dioxide. I. Composition of the Gas Phase and Partial Vapor Pressures of the Molecular Forms over Silicon Dioxide.

(63) Alexander, C. M. O. Exploration of Quantitative Kinetic Models for the Evaporation of Silicate Melts in Vacuum and in Hydrogen. Meteorit. Planet. Sci. 2001, 36 (2), 255-283. 
https://doi.org/10.1111/j.1945-5100.2001.tb01870.x.

(64) ALEXANDER, C. M. O. Application of MELTS to Kinetic Evaporation Models of FeOBearing Silicate Melts. Meteorit. Planet. Sci. 2002, 37 (2), 245-256. https://doi.org/10.1111/j.1945-5100.2002.tb01107.x.

(65) Kobayashi, K.; Sasaki, K.; Kon, M.; Fujii, H.; Watanabe, M. Kinetic Boundary Conditions for Vapor-Gas Binary Mixture. Microfluid. Nanofluidics 2017, 21 https://doi.org/10.1007/s10404-017-1887-6.

(66) Hirschwald, W.; Stranski, I. N. Theoretical Considerations and Experiments on Evaporation of Solids. In Condensation and evaporation of solids; Rutner, E., Goldfinger, P., Hirth, J. P., Eds.; Gordon and Breach, 1964; pp 59-85.

(67) Cappa, C. D.; Hendricks, M. B.; DePaolo, D. J.; Cohen, R. C. Isotopic Fractionation of Water during Evaporation. J. Geophys. Res. D Atmos. 2003, 108 (16). https://doi.org/10.1029/2003jd003597.

(68) Knacke, O.; Stranski, I. N. The Mechanism of Evaporation. Prog. Met. Phys. 1956, 6 (C). https://doi.org/10.1016/0502-8205(56)90007-7.

(69) Fujikawa, S.; Maerefat, M. A Study of the Molecular Mechanism of Vapour Condensation. JSME Int. journal. Ser. 2, Fluids Eng. heat Transf. power, Combust. Thermophys. Prop. 1990, 33 (4), 634-641. https://doi.org/10.1299/jsmeb1988.33.4_634.

(70) Bigeleisen, J.; Mayer, M. G. Calculation of Equilibrium Constants for Isotopic Exchange Reactions. J. Chem. Phys. 1947, 15 (5), 261-267. https://doi.org/10.1063/1.1746492.

(71) Estrade, N.; Carignan, J.; Sonke, J. E.; Donard, O. F. X. Mercury Isotope Fractionation 
during Liquid-Vapor Evaporation Experiments. Geochim. Cosmochim. Acta 2009, 73 (10), 2693-2711. https://doi.org/10.1016/j.gca.2009.01.024.

(72) Knight, K. B.; Kita, N. T.; Mendybaev, R. A.; Richter, F. M.; Davis, A. M.; Valley, J. W. Silicon Isotopic Fractionation of CAI-like Vacuum Evaporation Residues. Geochim. Cosmochim. Acta 2009, 73 (20), 6390-6401. https://doi.org/10.1016/j.gca.2009.07.008.

(73) Stewart, M. K. Stable Isotope Fractionation Due to Evaporation and Isotopic Exchange of Falling Waterdrops: Applications to Atmospheric Processes and Evaporation of Lakes. J. Geophys. Res. 1975, 80 (9), 1133-1146. https://doi.org/10.1029/jc080i009p01133.

(74) Wimpenny, J.; Marks, N.; Knight, K.; Rolison, J. M.; Borg, L.; Eppich, G.; Badro, J.; Ryerson, F. J.; Sanborn, M.; Huyskens, M. H.; et al. Experimental Determination of Zn Isotope Fractionation during Evaporative Loss at Extreme Temperatures. Geochim. Cosmochim. Acta 2019, 259, 391-411. https://doi.org/10.1016/j.gca.2019.06.016.

(75) Fonda, G. R. Evaporation of Tungsten under Various Pressures of Argon. Phys. Rev. 1928, 31 (2), 260-266. https://doi.org/10.1103/PhysRev.31.260.

(76) Longini, R. L. Evaporation and Outgassing in an Inert Atmosphere. J. Appl. Phys. 1950, 21 (2), 81-83. https://doi.org/10.1063/1.1699627.

(77) Naumann, R. J.; Russell, W. M.; Marshall, G. C. Nasa Technical Memorandum NASATMX64639 The Effect of Ambient Pressure on the Evaporation Rate of Materials; 1972.

(78) Chapman, S. The Mathematical Theory of Non-Uniform Gases, 2nd ed.; Cambridge University Press: Cambridge Eng., 1953.

(79) Lilov, S. K. Determination of the Effective Kinetic Diameter of the Complex Molecules. 
Cryst. Res. Technol. 1986, 21 (10), 1299-1302. https://doi.org/10.1002/crat.2170211011.

(80) Safarian, J.; Engh, T. A. Vacuum Evaporation of Pure Metals. Metall. Mater. Trans. A Phys. Metall. Mater. Sci. 2013, 44 (2), 747-753. https://doi.org/10.1007/s11661-012-1464-2.

(81) Crank, J. The Mathematics of Diffusion; Clarendon Press, 1975.

(82) Fedkin, A. V.; Grossman, L.; Ciesla, F. J.; Simon, S. B. Mineralogical and Isotopic Constraints on Chondrule Formation from Shock Wave Thermal Histories. Geochim. Cosmochim. Acta 2012, 87, 81-116. https://doi.org/10.1016/j.gca.2012.03.020.

(83) Wombacher, F.; Rehkämper, M.; Mezger, K.; Bischoff, A.; Münker, C. Cadmium Stable Isotope Cosmochemistry. Geochim. Cosmochim. Acta 2008, 72 (2), 646-667. https://doi.org/10.1016/j.gca.2007.10.024.

(84) Albarède F. Volatile Accretion History of the Terrestrial Planets and Dynamic Implications. Nature 2009, 461 (7268), 1227-1233.

(85) Trinquier, A.; Birck, J.; Allegre, C. J. Widespread 54 Cr Heterogeneity in the Inner Solar System . Astrophys. J. 2007, 655 (2), 1179-1185. https://doi.org/10.1086/510360.

(86) Benedikt, M. R.; Scherf, M.; Lammer, H.; Marcq, E.; Odert, P.; Leitzinger, M.; Erkaev, N. V. Escape of Rock-Forming Volatile Elements and Noble Gases from Planetary Embryos. Icarus 2020, 347, 113772. https://doi.org/10.1016/j.icarus.2020.113772.

(87) Cuzzi, J. N.; Alexander, C. M. O. D. Chondrule Formation in Particle-Rich Nebular Regions at Least Hundreds of Kilometres Across. Nature 2006, 441 (7092), 483-485. https://doi.org/10.1038/nature04834. 
(88) Carrier, O.; Shahidzadeh-Bonn, N.; Zargar, R.; Aytouna, M.; Habibi, M.; Eggers, J.; Bonn, D. Evaporation of Water: Evaporation Rate and Collective Effects. J. Fluid Mech. 2016, 798, 774-786. https://doi.org/10.1017/jfm.2016.356.

(89) Ebel, D. S.; Grossman, L. Condensation in Dust-Enriched System. Geochim. Cosmochim. Acta 2000, 64 (2), 339-366. https://doi.org/10.1016/S0016-7037(99)00284-7.

(90) Costa, G. C. C.; Jacobson, N. S.; Fegley, B. Vaporization and Thermodynamics of Forsterite-Rich Olivine and Some Implications for Silicate Atmospheres of Hot Rocky Exoplanets. Icarus 2017, 289, 42-55. https://doi.org/10.1016/j.icarus.2017.02.006.

(91) Lamoreaux, R. H.; Hildenbrand, D. L.; Brewer, L. High-Temperature Vaporization Behavior of Oxides II. Oxides of Be, Mg, Ca, Sr, Ba, B, Al, Ga, In, Tl, Si, Ge, Sn, Pb, Zn, Cd, and Hg. J. Phys. Chem. Ref. Data 1987, 16 (3), 419-443. https://doi.org/10.1063/1.555799.

(92) Alexander, C. M. O. D.; Grossman, J. N.; Ebel, D. S.; Ciesla, F. J. The Formation Conditions of Chondrules and Chondrites. Science (80-. ). 2008, 320, 1617-1619.

(93) Habfast, K. Fractionation in the Thermal Ionization Source. Int. J. Mass Spectrom. Ion Phys. 1983, 51 (2-3), 165-189. https://doi.org/10.1016/0020-7381(83)85004-9.

(94) Kanno, H. Isotopic Fractionation in a Thermal Ion Source. Bull. Chem. Soc. Jpn. 1971, 44 (7), 1808-1812. https://doi.org/10.1246/bcsj.44.1808.

(95) Trinquier, A.; Birck, J. L.; Allègre, C. J. High-Precision Analysis of Chromium Isotopes in Terrestrial and Meteorite Samples by Thermal Ionization Mass Spectrometry. J. Anal. At. Spectrom. 2008, 23 (12), 1565-1574. https://doi.org/10.1039/b809755k. 
(96) Caro, G.; Bourdon, B.; Birck, J.-L.; Moorbath, S. High-Precision ${ }^{142} \mathrm{Nd} /{ }^{144} \mathrm{Nd}$ Measurements in Terrestrial Rocks: Constraints on the Early Differentiation of the Earth's $\begin{array}{llll}\text { Mantle. Geochim. } & \text { Cosmochim. } & \text { Acta } & \end{array}$ https://doi.org/10.1016/j.gca.2005.08.015.

(97) Tang, H.; Dauphas, N. Abundance, Distribution, and Origin of 60Fe in the Solar Protoplanetary Disk. Earth Planet. Sci. Lett. 2012, 359-360, 248-263. https://doi.org/10.1016/j.epsl.2012.10.011.

(98) Haring, M. Crystal Structure and Al/Si Cation Ordering in "Fassaite": A Combined Single Crystal, 27Al and 29Si NMR Study. Electron. Thesis Diss. Repos. 2012.

(99) Guillot, B.; Sator, N. A Computer Simulation Study of Natural Silicate Melts. Part I: Low Pressure Properties. Geochim. Cosmochim. Acta 2007, 71 (5), 1249-1265. https://doi.org/10.1016/j.gca.2006.11.015. 
Figure 1

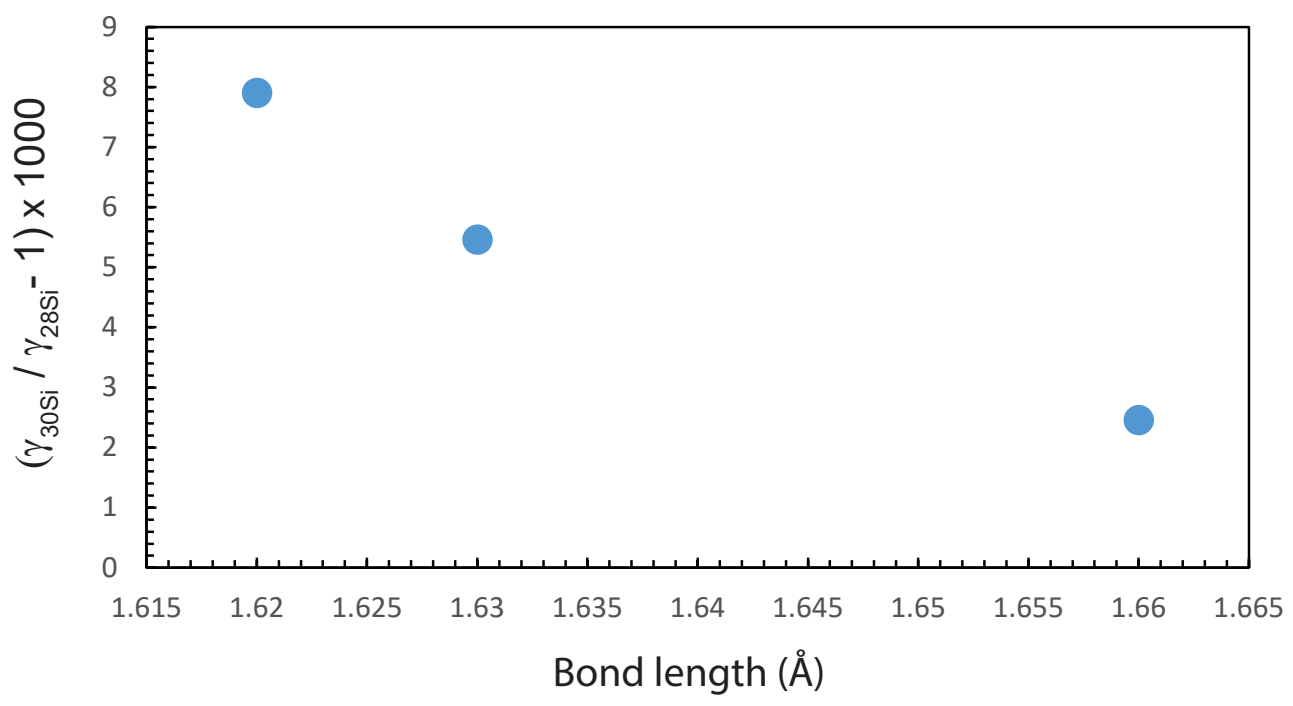


Figure 2

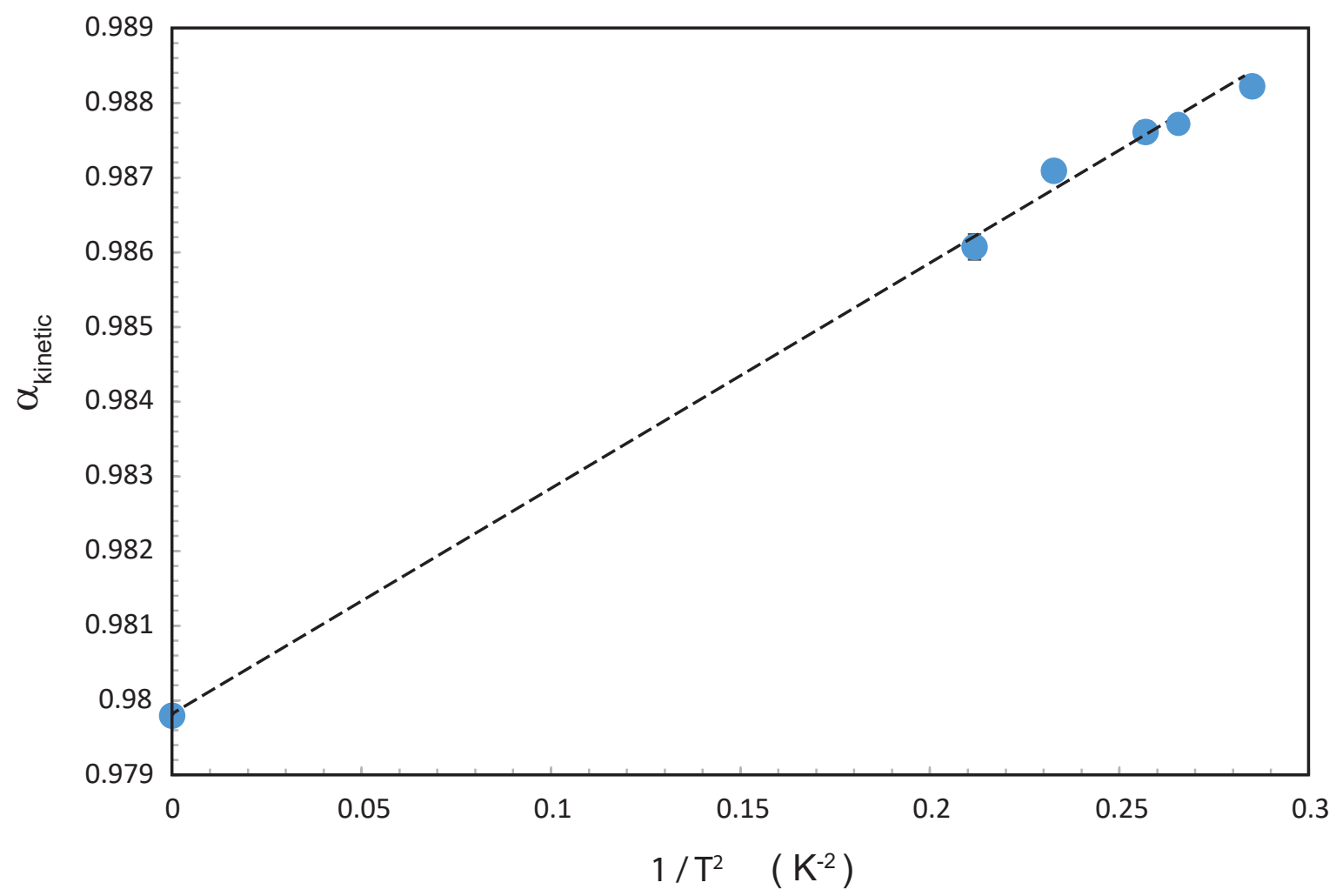


Figure 3

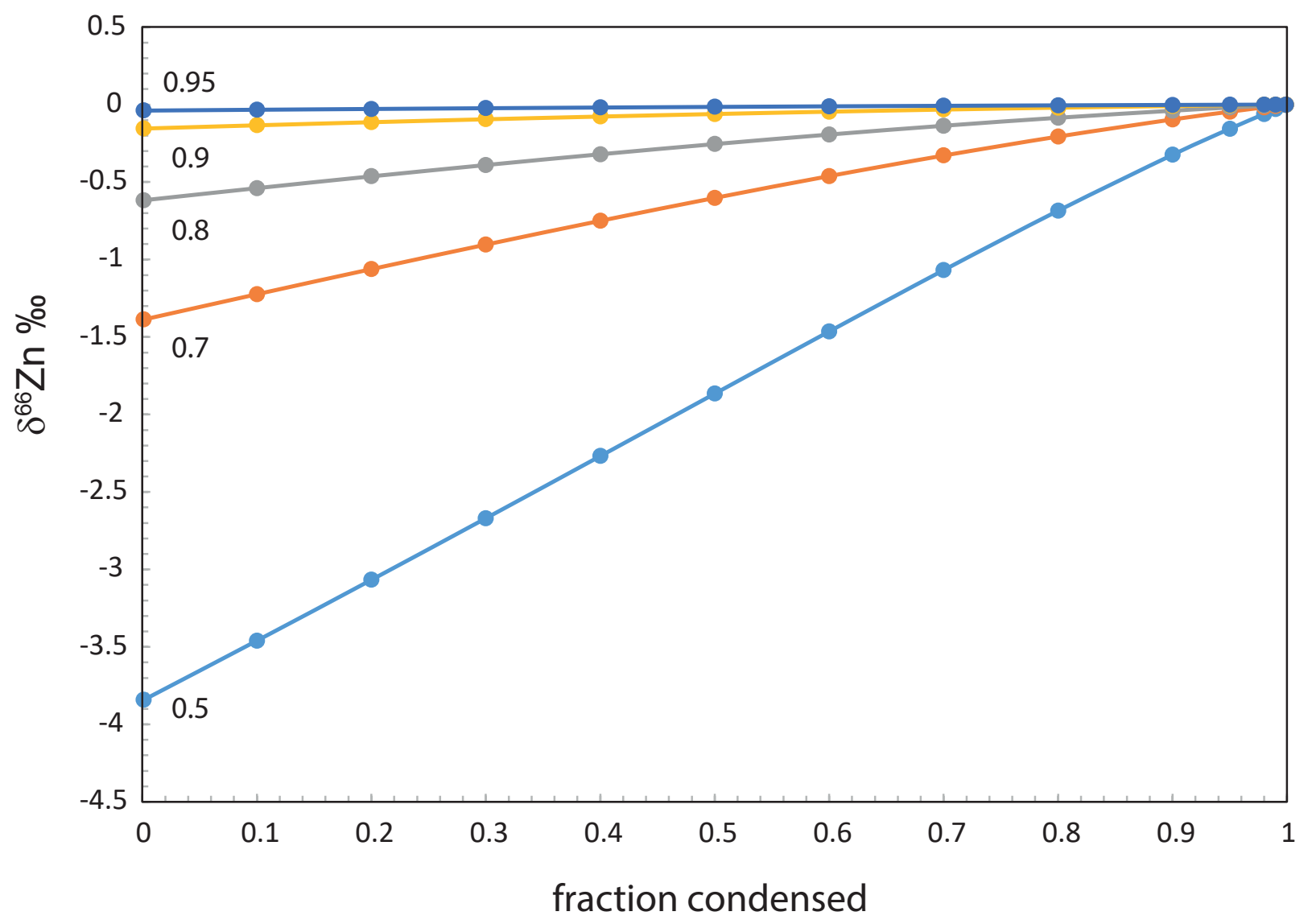


Figure 4

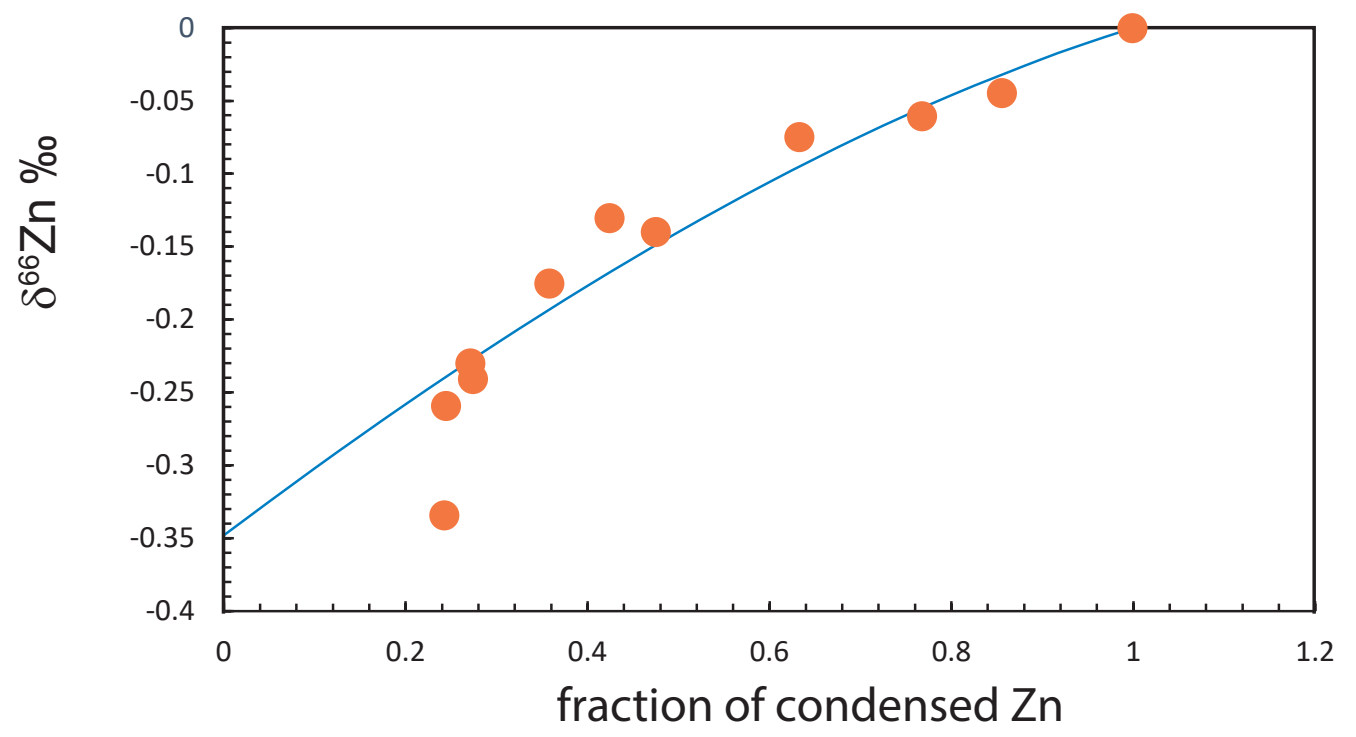


Figure 5

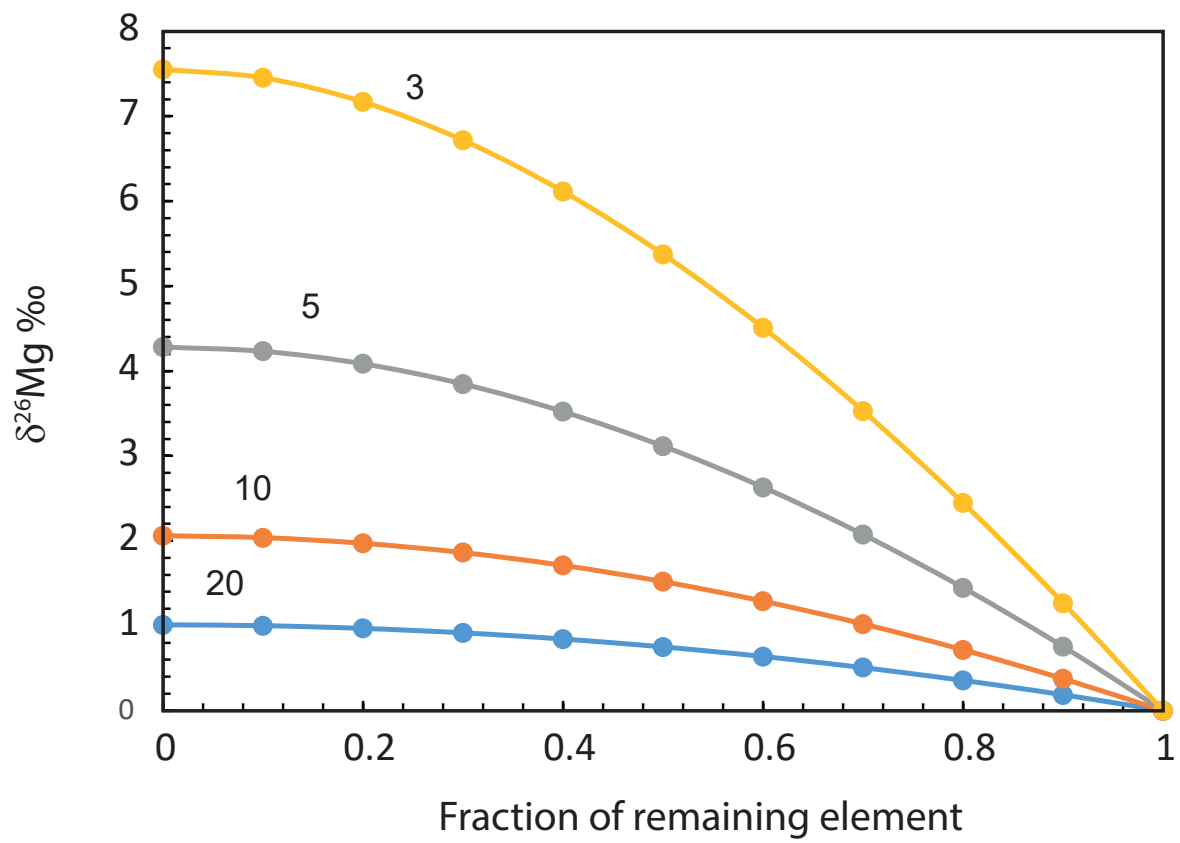


Figure 6

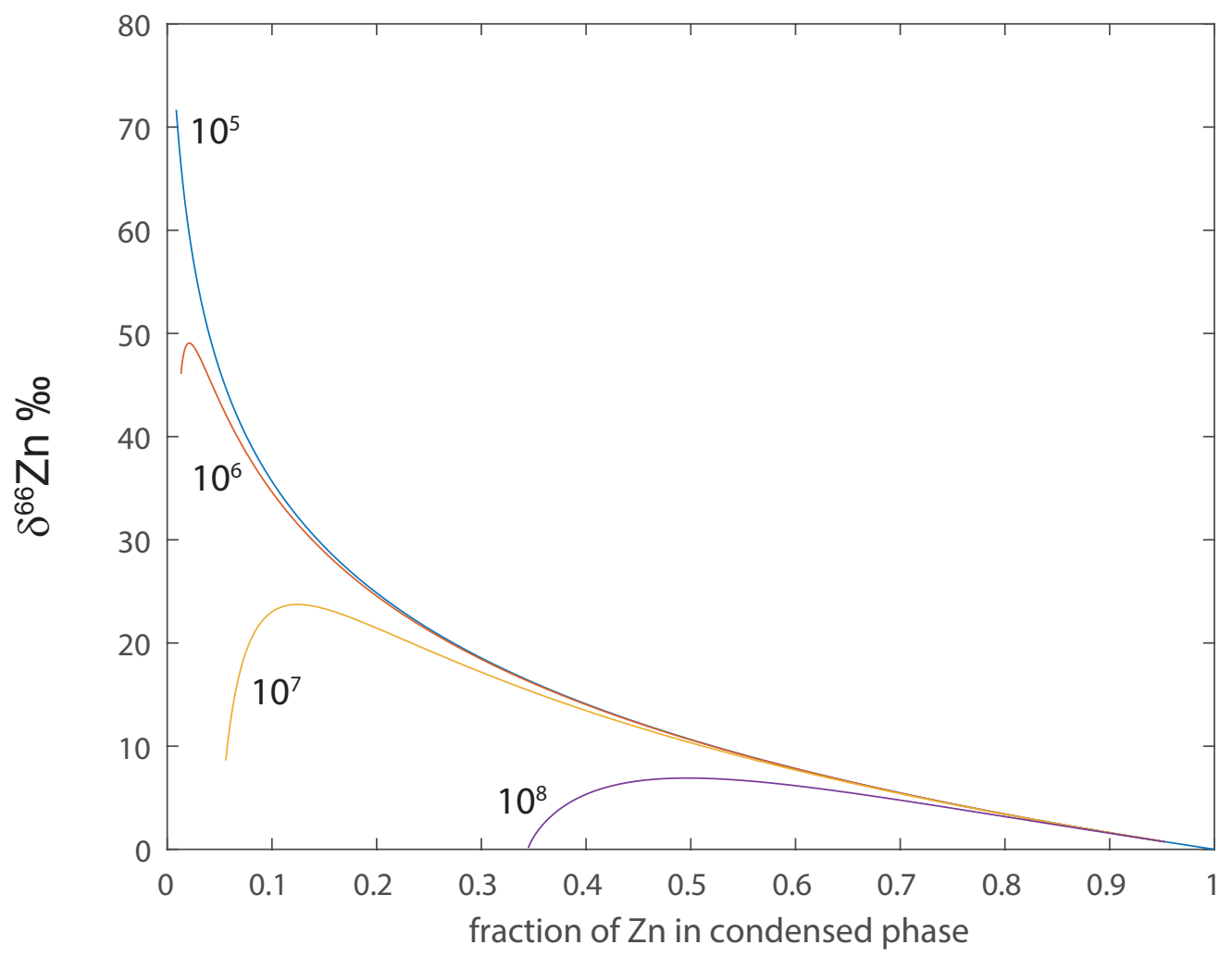


Figure 7a

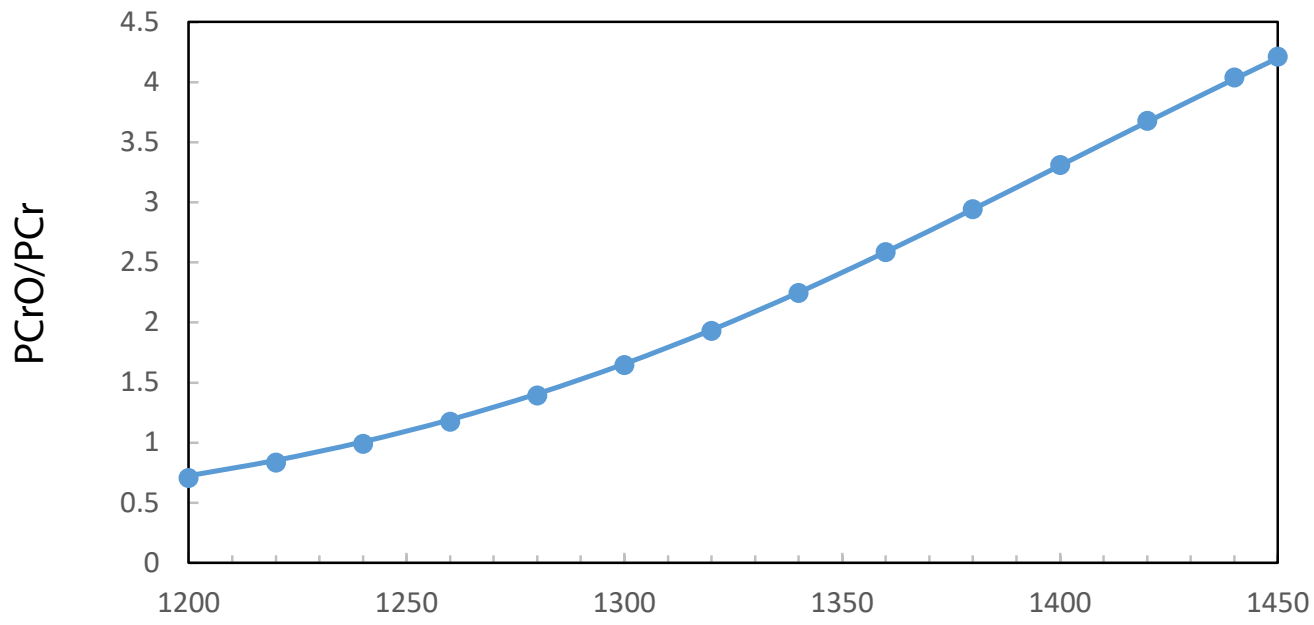

Temperature ${ }^{\circ} \mathrm{C}$ 
Figure $7 b$

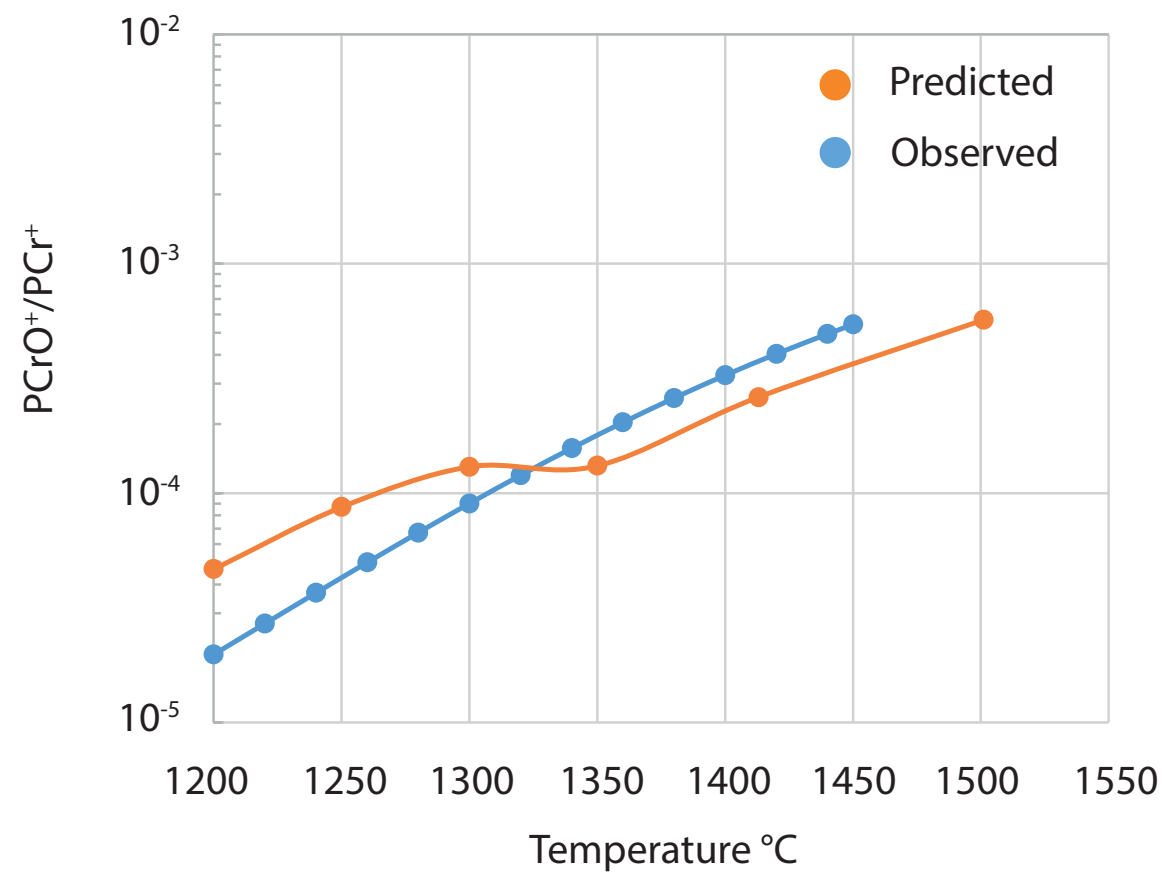


Figure 8

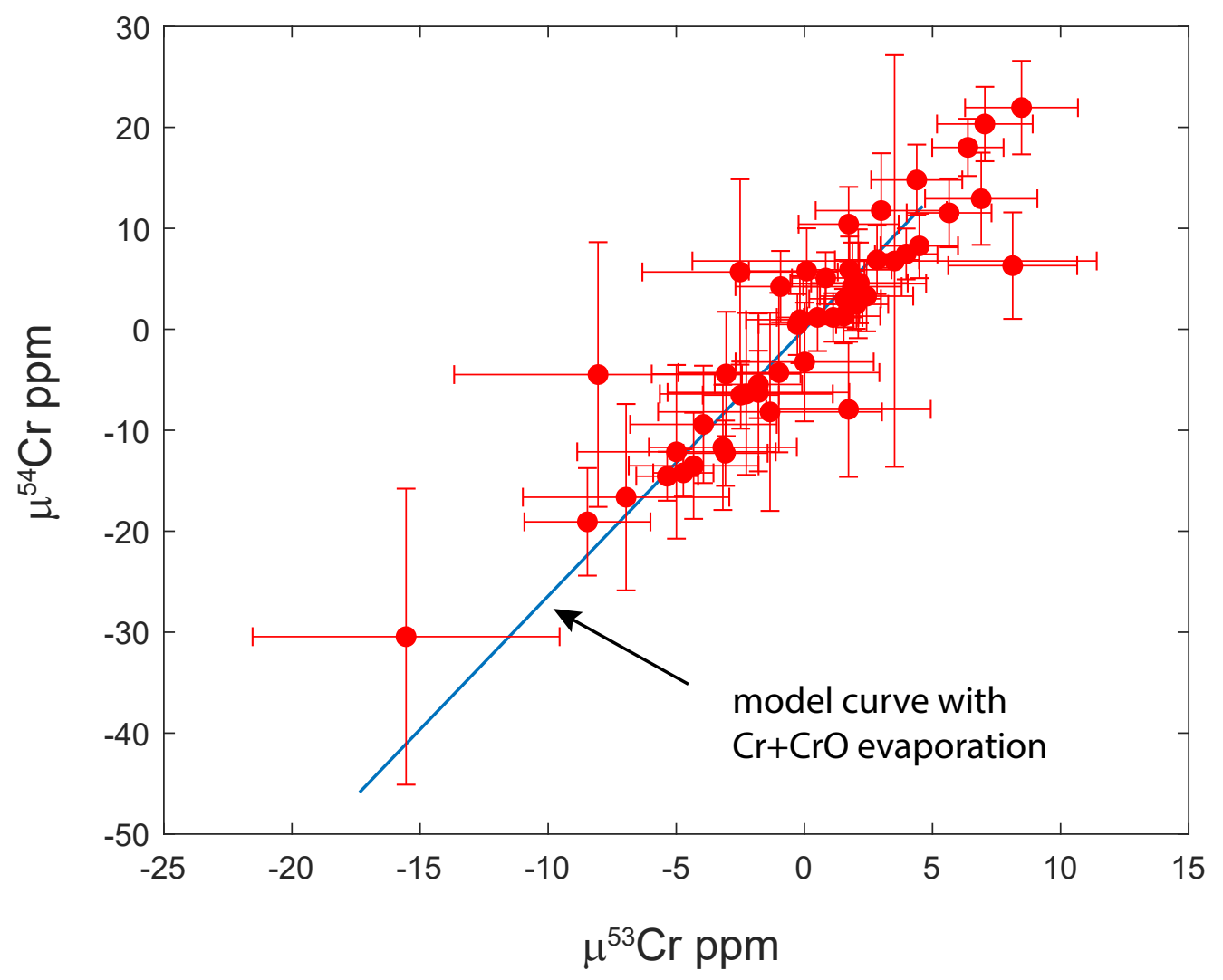


Cr isotope NIST SRM 979 standard measurements by TIMS normalized to ${ }^{50} \mathrm{Cr} /{ }^{52} \mathrm{Cr}$ ratios

\begin{tabular}{|c|c|c|c|c|}
\hline & $\mu^{53} \mathrm{Cr}(\mathrm{ppm})$ & \pm & $\mu^{52} \mathrm{Cr}(\mathrm{ppm})$ & \pm \\
\hline $\mathrm{Cr} 1$ & 8.474679942 & 2.2021565 & 21.9554544 & 4.6255275 \\
\hline $\mathrm{Cr} 2$ & 2.427300466 & 1.81971524 & 3.27835795 & 3.48396271 \\
\hline $\mathrm{Cr} 3$ & 0.089084006 & 2.25567627 & 5.76769471 & 4.23498935 \\
\hline $\mathrm{Cr} 4$ & 4.384464512 & 1.77778781 & 14.7910523 & 3.50348298 \\
\hline Cr5 & 1.121793074 & 1.14398448 & 1.16837641 & 2.39983482 \\
\hline Cr6 & -0.274792922 & 1.51403698 & 0.47036042 & 3.0149698 \\
\hline $\mathrm{Cr} 7$ & -3.080305903 & 1.64345427 & -12.2742442 & 3.23392704 \\
\hline $\mathrm{Cr} 8$ & 1.763301204 & 1.63659357 & 5.89165824 & 3.29136982 \\
\hline $\mathrm{Cr} 9$ & 6.381529468 & 1.39241548 & 18.0149991 & 2.83108471 \\
\hline Cr10 & 0.832672634 & 1.31757605 & 5.07520872 & 2.56331776 \\
\hline Cr11 & 3.973717065 & 1.21971726 & 7.45698304 & 2.5218697 \\
\hline Cr12 & 7.043058485 & 1.86692693 & 20.3312122 & 3.68571318 \\
\hline Cr13 & -1.794713401 & 1.7046754 & -5.46161468 & 3.34133553 \\
\hline Cr14 & 4.48331664 & 1.51363019 & 8.25521434 & 3.19678548 \\
\hline Cr15 & 5.648057219 & 1.65527865 & 11.5297808 & 3.41079564 \\
\hline Cr16 & 0.511821039 & 1.58854808 & 1.17344104 & 3.3259614 \\
\hline Cr17 & -2.484169041 & 1.48418741 & -6.52088358 & 3.32102485 \\
\hline Cr18 & 2.146175526 & 1.88549067 & 4.5935873 & 3.99219481 \\
\hline Cr19 & -0.930206482 & 1.76038451 & 4.22497107 & 3.53291415 \\
\hline $\mathrm{Cr} 20$ & 2.027901823 & 1.24179881 & 2.46908018 & 2.42637096 \\
\hline $\mathrm{Cr} 21$ & 1.586801011 & 1.39961523 & 3.01843291 & 2.82068239 \\
\hline $\mathrm{Cr} 22$ & 1.53301733 & 1.42766085 & 1.29782145 & 2.69269106 \\
\hline $\mathrm{Cr} 23$ & -4.724548746 & 1.1761779 & -14.218361 & 2.34337966 \\
\hline $\mathrm{Cr} 24$ & -5.355044294 & 1.20686449 & -14.5553509 & 2.42699068 \\
\hline $\mathrm{Cr} 25$ & 2.101088322 & 2.64963892 & 4.50865271 & 5.38879352 \\
\hline Cr26 & -0.176044741 & 2.09828258 & 0.95241318 & 4.30612787 \\
\hline Cr27 & -3.940180426 & 2.86047856 & -9.41887443 & 5.810652 \\
\hline $\mathrm{Cr} 28$ & -15.54549623 & 5.99130928 & -30.444806 & 14.6580426 \\
\hline $\mathrm{Cr} 29$ & -6.958810135 & 4.028339 & -16.6329952 & 9.23081816 \\
\hline $\mathrm{Cr} 30$ & 2.835018635 & 1.64216503 & 6.87800198 & 3.39523838 \\
\hline Cr31 & -4.323311201 & 2.53369778 & -13.5206161 & 5.25783126 \\
\hline $\mathrm{Cr} 32$ & 1.726889894 & 1.95446067 & 10.4112542 & 3.68900034 \\
\hline $\mathrm{Cr} 33$ & -1.341706982 & 4.36776016 & -8.18337524 & 9.80940369 \\
\hline Cr34 & -3.054556198 & 2.90379082 & -4.42544306 & 6.15725233 \\
\hline Cr35 & -3.181153336 & 2.88572317 & -11.6973283 & 6.2019936 \\
\hline Cr36 & -8.468347088 & 2.46002168 & -19.074081 & 5.32536287 \\
\hline Cr37 & -2.267020295 & 3.37505364 & -6.40340096 & 8.02132214 \\
\hline $\mathrm{Cr} 38$ & 6.901343534 & 2.19144264 & 12.9271474 & 4.56646529 \\
\hline Cr39 & -1.793500957 & 3.54673195 & -6.25383598 & 7.81938212 \\
\hline $\mathrm{Cr} 40$ & 2.998082015 & 2.55811645 & 11.7579298 & 5.67884564 \\
\hline Cr41 & 0.009387322 & 2.69450774 & -3.23866402 & 5.8795187 \\
\hline $\mathrm{Cr} 42$ & -4.993330368 & 3.87265717 & -12.13695 & 8.60305039 \\
\hline $\mathrm{Cr} 43$ & 8.129857841 & 2.51627332 & 6.30170606 & 5.27339293 \\
\hline $\mathrm{Cr} 44$ & -8.053449875 & 5.61605149 & -4.48279632 & 13.1087888 \\
\hline
\end{tabular}




\begin{tabular}{ccccc} 
Cr45 & -0.995342829 & 3.92196686 & -4.28707662 & 7.89487311 \\
Cr46 & 3.519561672 & 7.89046579 & 6.76617199 & 20.3888278 \\
Cr47 & -2.509704386 & 3.81396142 & 5.67736798 & 9.18284739 \\
Cr48 & 1.874367843 & 1.92115258 & 4.21850153 & 4.36536969 \\
Cr49 & 1.72144733 & 3.20971366 & -7.93213596 & 6.68687137 \\
\hline
\end{tabular}

Normalizing ratio : ${ }^{50} \mathrm{Cr} /{ }^{52} \mathrm{Cr}=0.05185853$ 